دراسة اقتصادية للجدارة الإتتاجية للأراضى الزراعية بمحافظة الو ادى الجديد

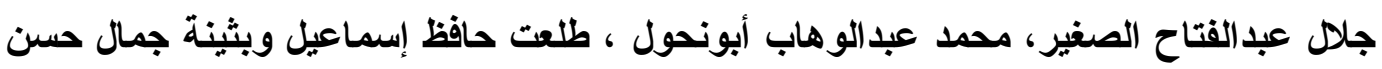
صبره

$$
\text { قسم الأقتصاد الزر اعى - كلية الزر اعة - جامعة أسيوط }
$$

تعتبر المو ارد الأرضية الزر اعية من أهم المو ارد الاقتصادية والتى تلعب الدور الأكبر فى الإقى

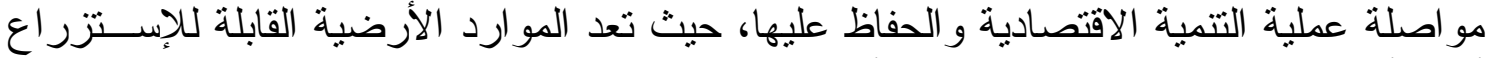

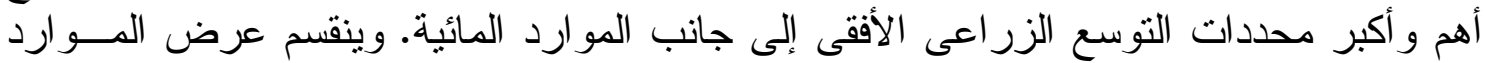

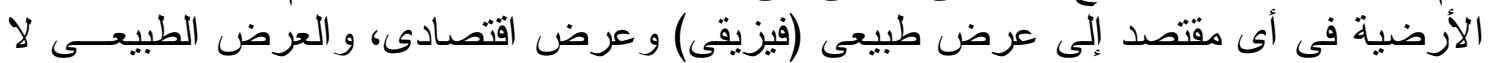

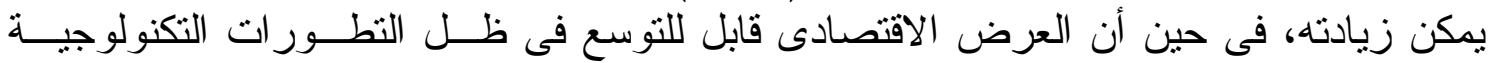

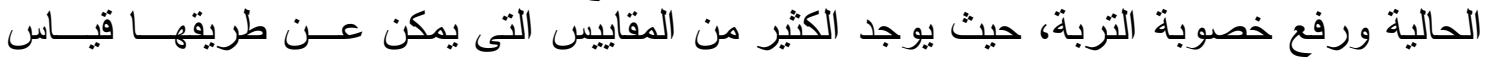

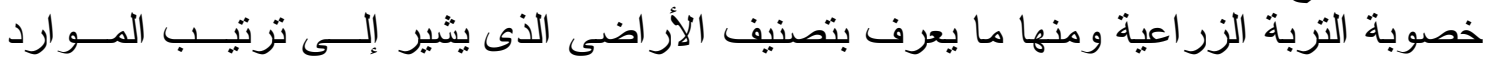

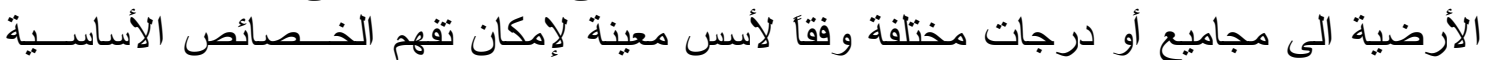

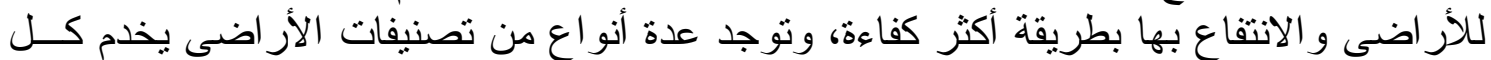

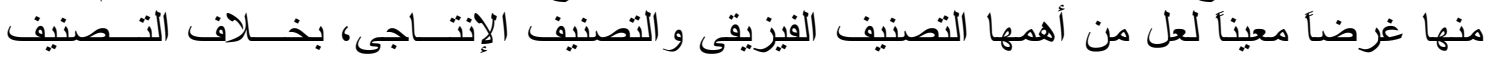

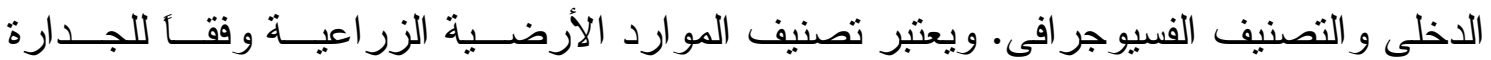

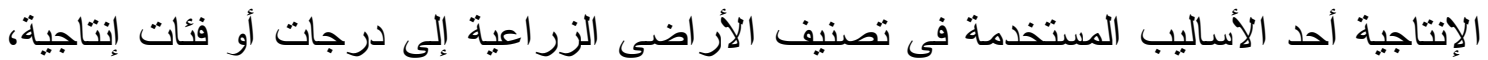

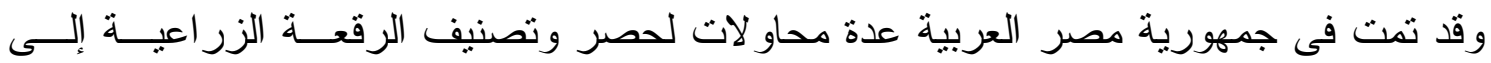

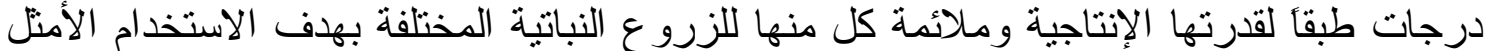

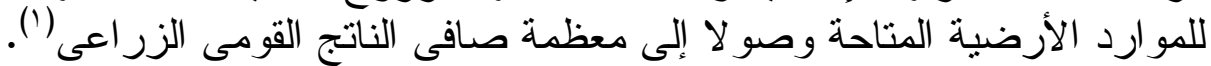

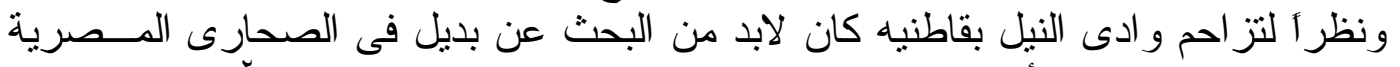

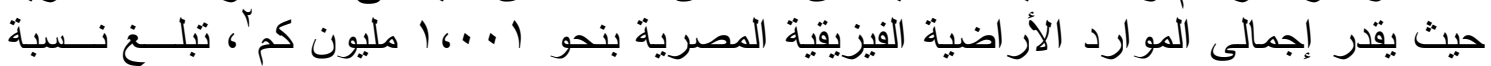

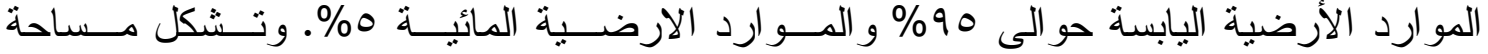

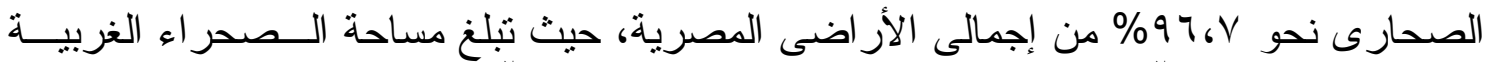

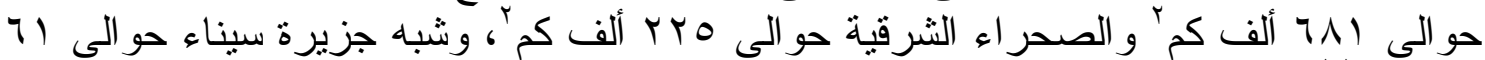

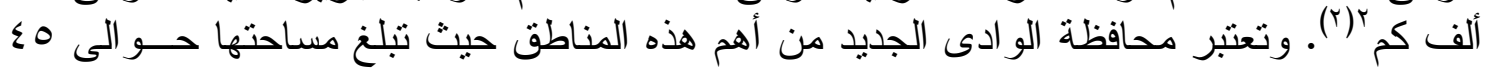

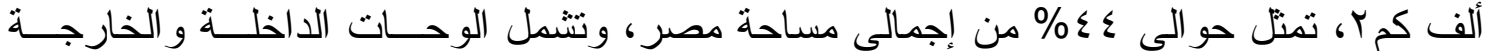
و الفر افرة وشرق العوينات (").

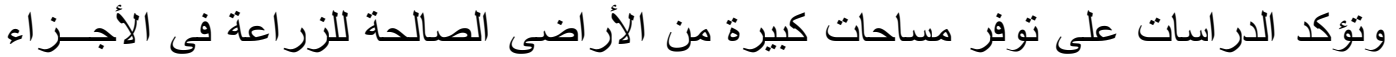

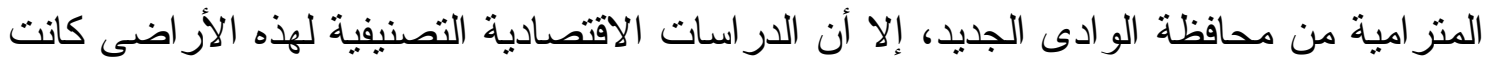

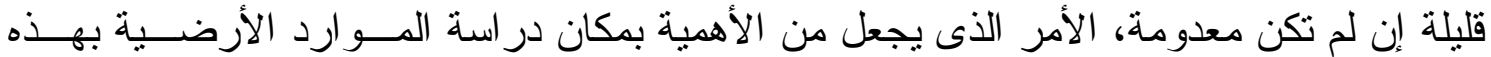

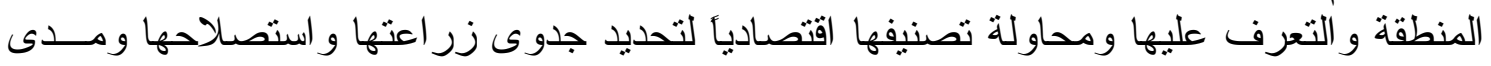
مساهمتها فى حل جزء من مشاكل قطاع الزر اعة المصرى فى توفير الامن التهن الغذائى للسكان.

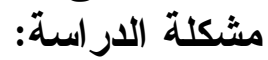

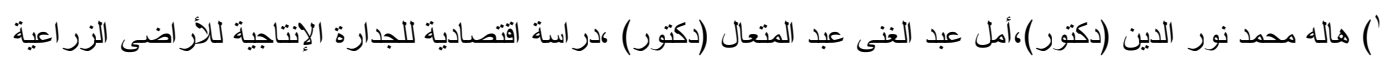

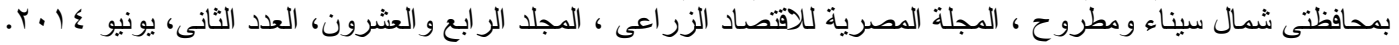

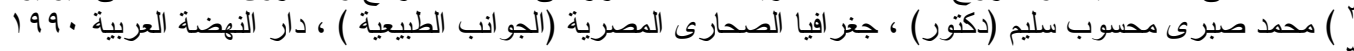

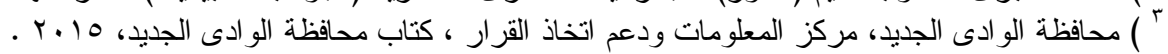


تعانى جمهورية مصر العربية من فجوة غذائية و اضحة و التى تعزى إلى عو امل طبيعيــة

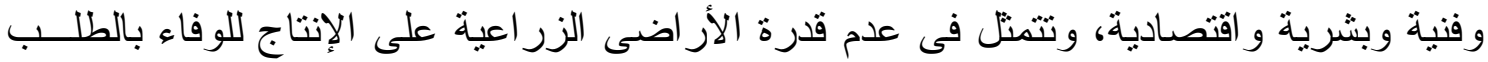

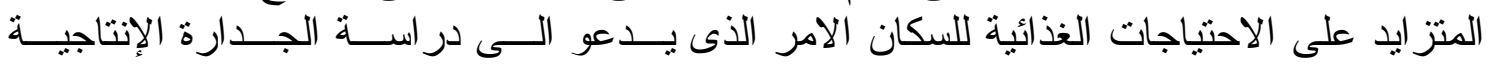

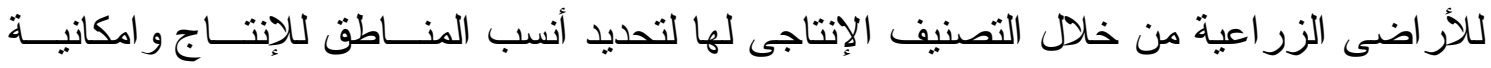

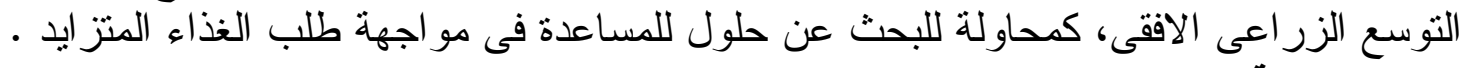
هدف اللدر استة:

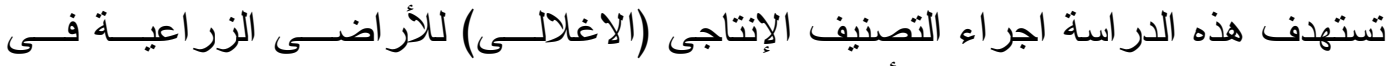

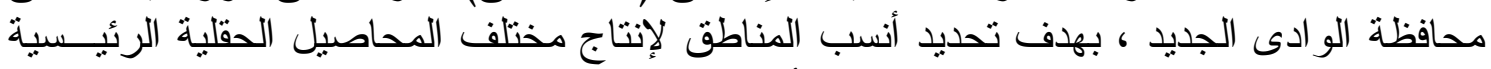

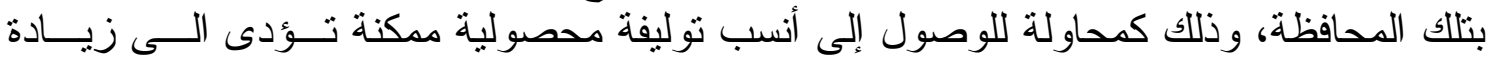

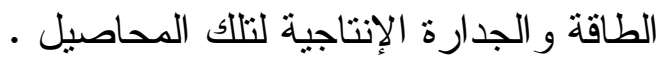
أهمية الار اسةة:

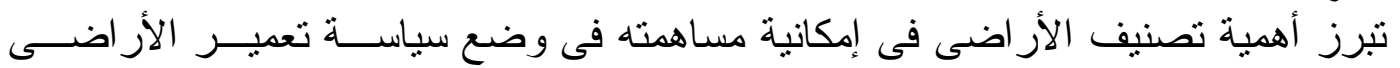

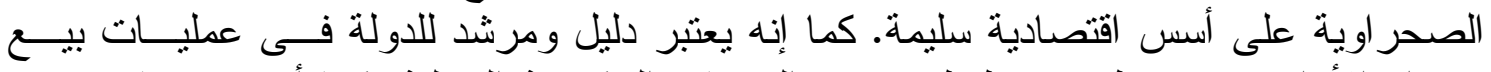

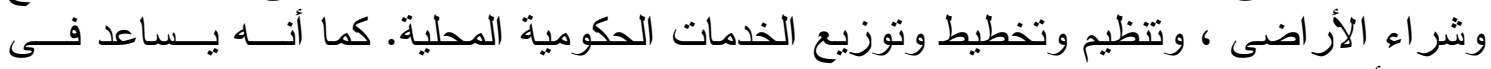

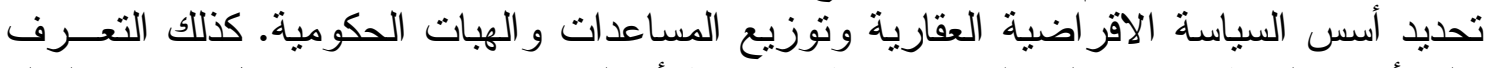

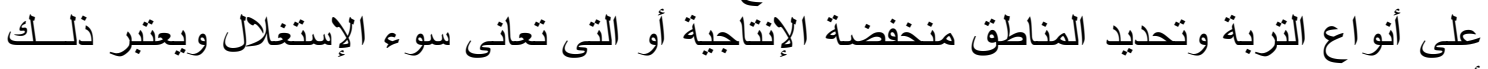

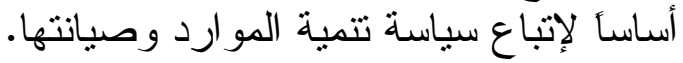

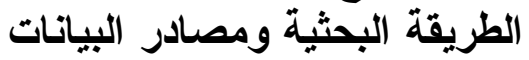

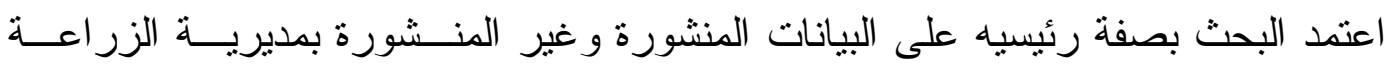

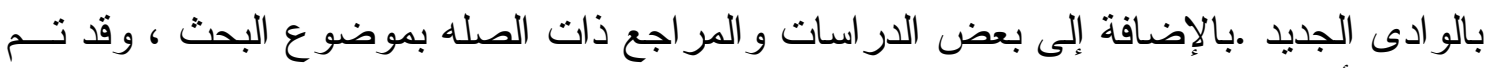

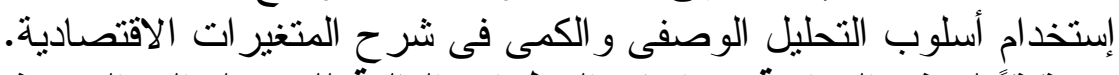

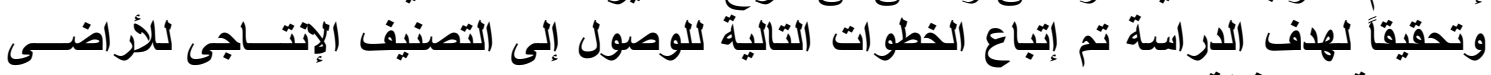

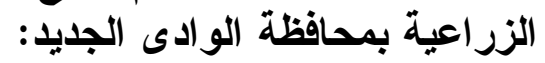

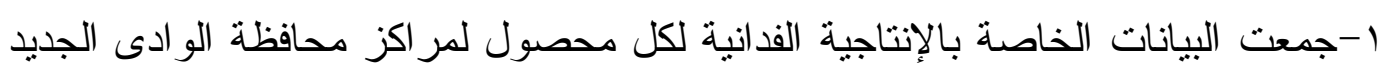

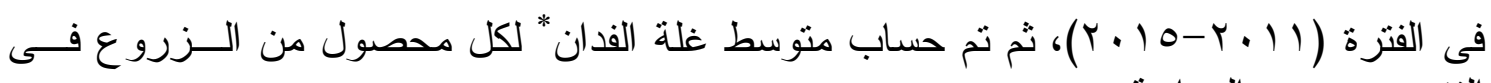

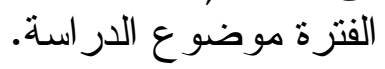

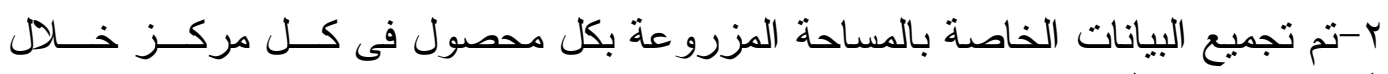

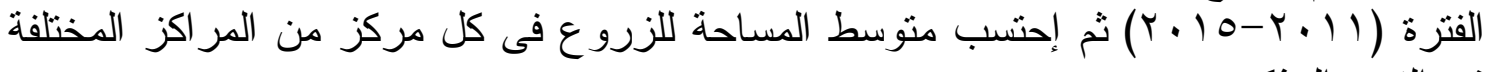
فى الفترة المذكورة.

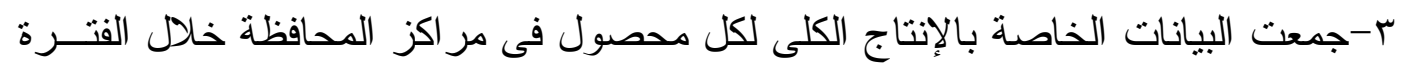

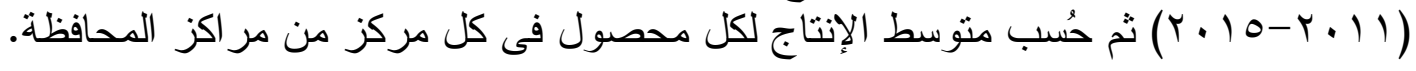

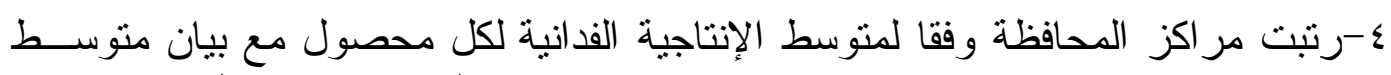

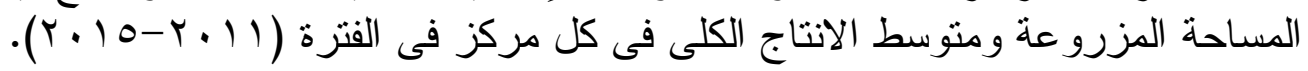

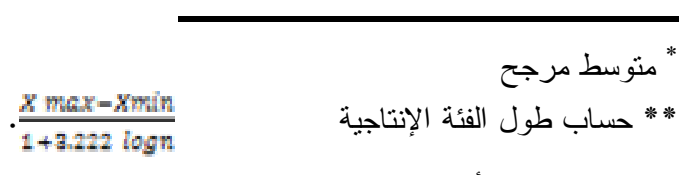

حيث [X max] أعلى متوسط لغلة الفدان لكل محصول ، [n] عدد المر اكز التى تزرع المحصول ، [X min] أدنى منوسط لغلة

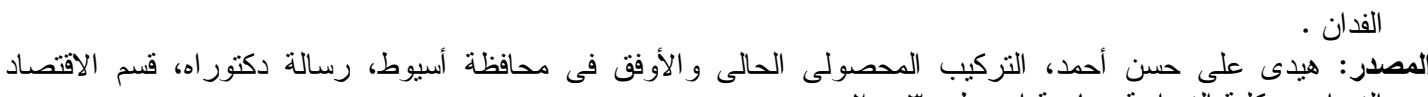

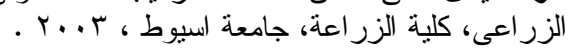




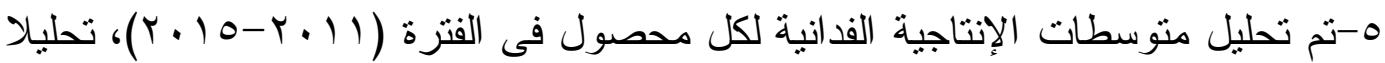
احصائيا لتقدير الفروق الإنتاجية التى تميز المتوسطات المختلفة عن بعضها، وبذلك أمكن تحديد

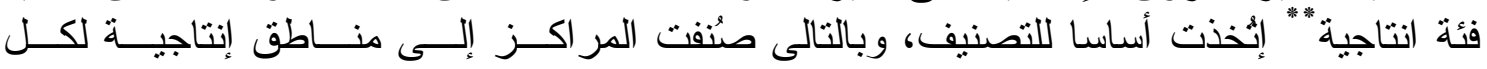

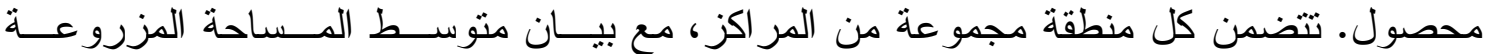

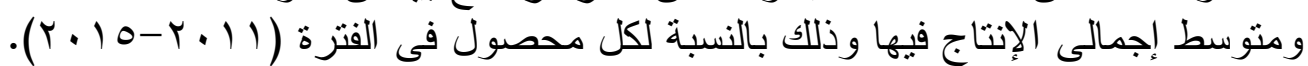

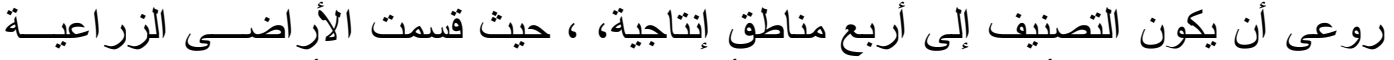
التى تتتج كل محصول إلى أربع مناطق إنتاجية أفضلها المنطقة الإنتاجية الأولى وهى التهى التى تضم الته الأر اضى الزر اعية التى لها أعلى جدارة إنتاجية للمحصول محل البحث و أقلها المنطقة الإنتاجية

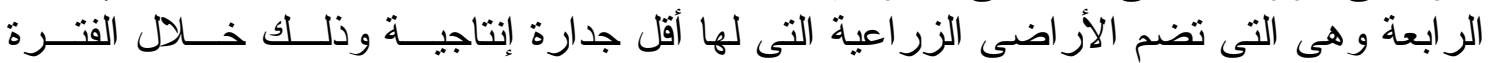

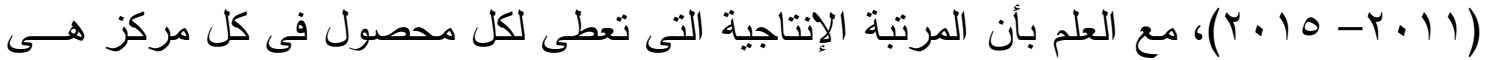

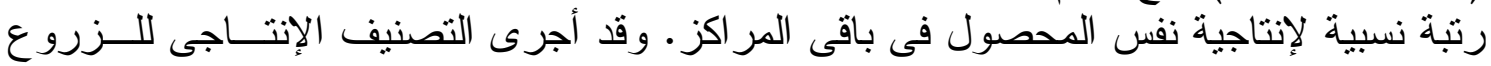

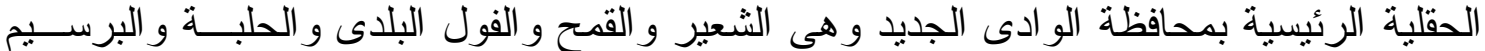

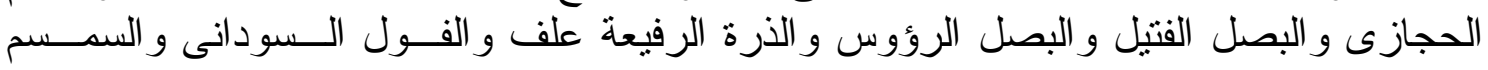

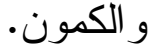
نتائج الدر استة: أولا: التصنيف الإتتاجى للزروع النباتية :

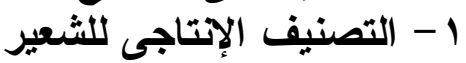

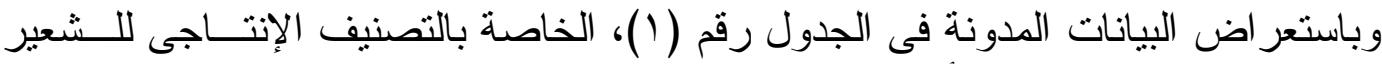
أمكن تقيسم المناطق الإنتاجية إلى أربع مناطق مختلفئة الجدول أ- - تضم المنطقة الإنتاجية الأولى مركز الداخلة حيث تر اوح منوسط الإنتاجية الفدانيــة

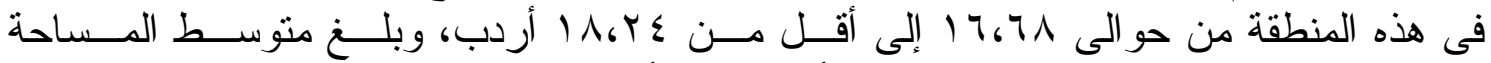

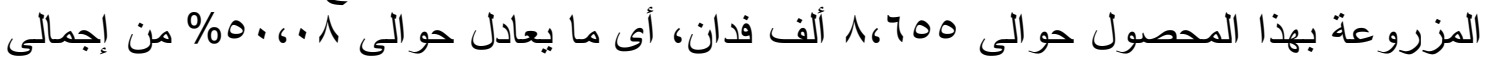

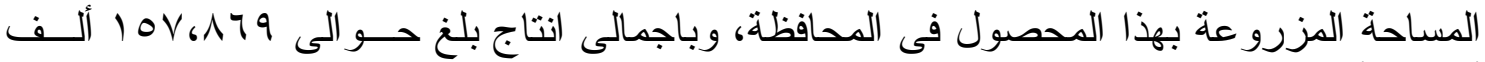

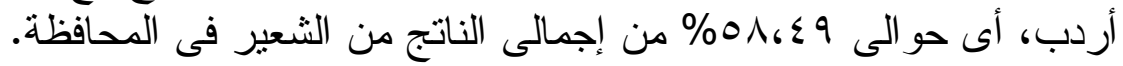

ب- كما تضمت المنطقة الإنتاجية الثانية مركز باريس، وتر اوح منتوسط الإنتاجية الفدانيــة

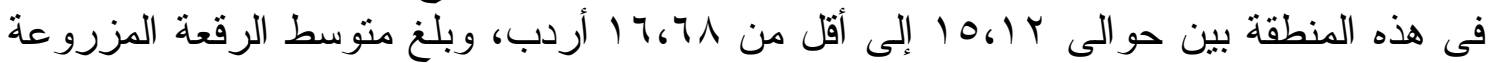

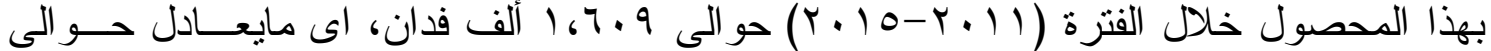

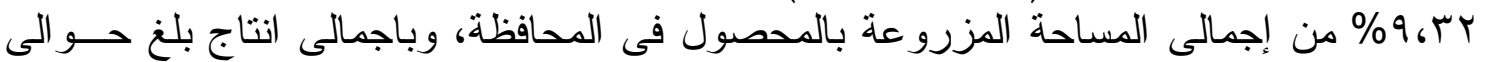

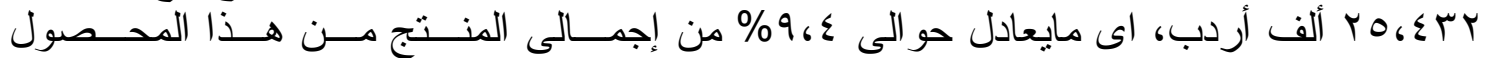
بالمحافظة.

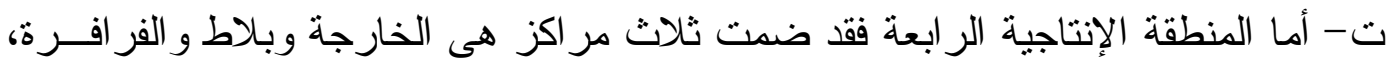

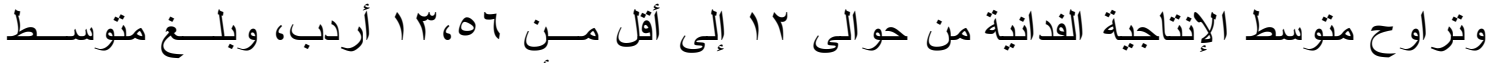

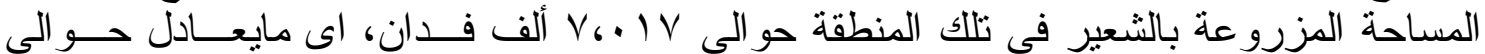

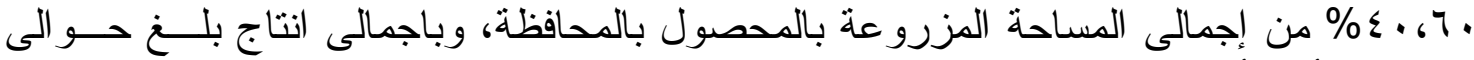

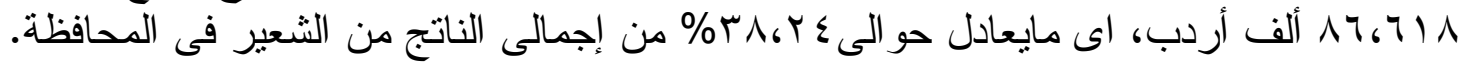


جدول ا ـ المناطق الإنتاجية لمحصول الثعير و متوسط المساحة المزروعة ومتوسط الإتتاج بالأردب

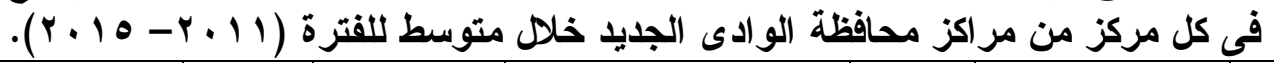

\begin{tabular}{|c|c|c|c|c|c|c|c|}
\hline$\%$ & الإنتاج & $\%$ & $\begin{array}{l}\text { متوسطة } \\
\text { (فُان) }\end{array}$ & اسماء المر اكز & المر اكز & الفئة الإتتاجية & الإلتاجية \\
\hline $0 \Lambda_{6} \leqslant 9$ & 10V^า9 & 0.6 .1 & 170061. & الداخلة & 1 & $1 N_{6} Y \varepsilon-17,71$ & 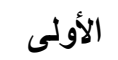 \\
\hline $96 \varepsilon$ & TOSTYIO & $9, r 5$ & 17.9674 & باريس & 1 & $17.71-10.14$ & الثانية \\
\hline- & - & - & - & - & - & $10,1 Y-116.07$ & الثالثة \\
\hline rN, & 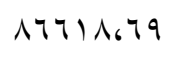 & $\varepsilon \cdot 67$. & $V .1 V$ & الخارجة -بلاط -الفر افرة & r & $1 \% .07-14$ & 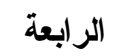 \\
\hline
\end{tabular}

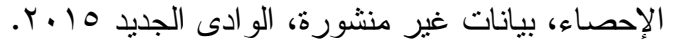

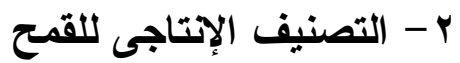

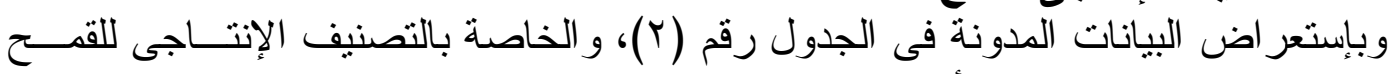

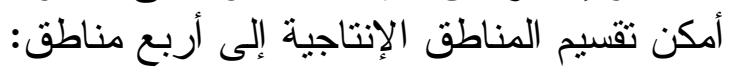

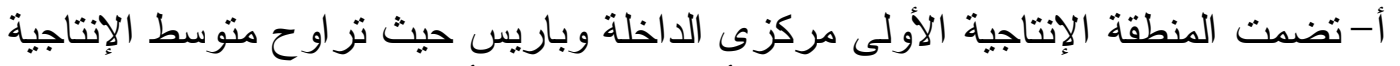

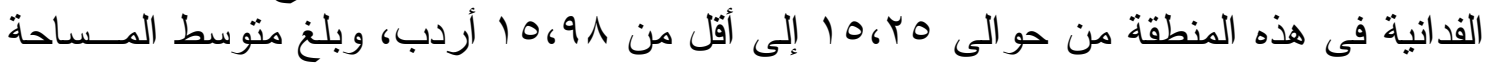

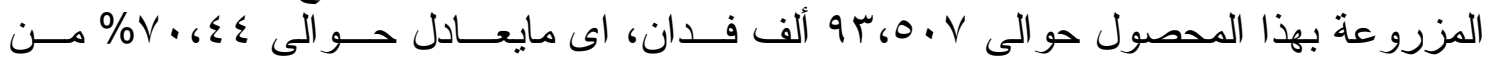

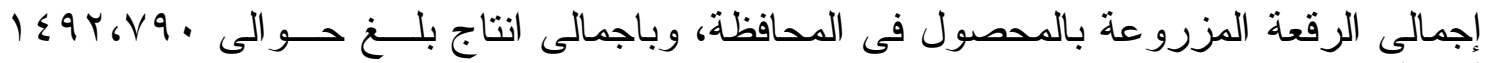

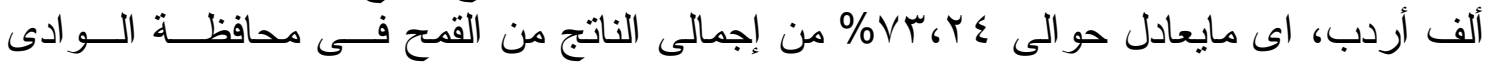

ب- كما تضمت المنطقة الإنتاجية الثالثة مركز الفر افرة، وتز اوح متوسط الإنتاجية الفدانية

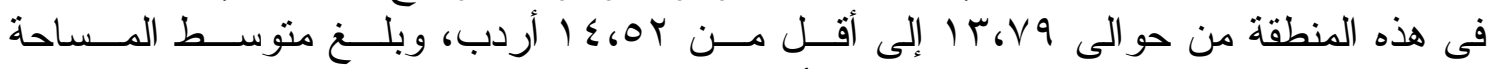

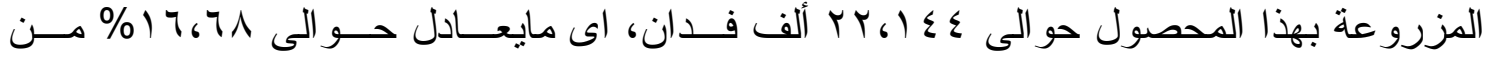

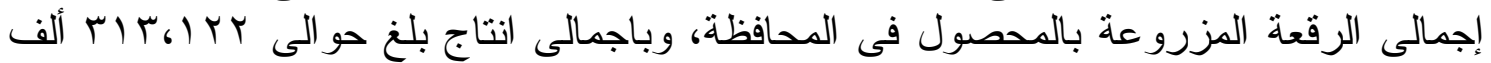

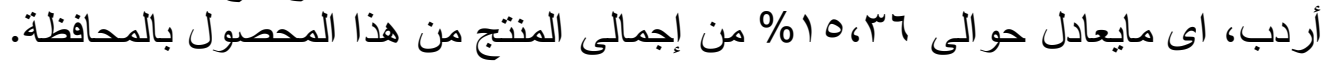

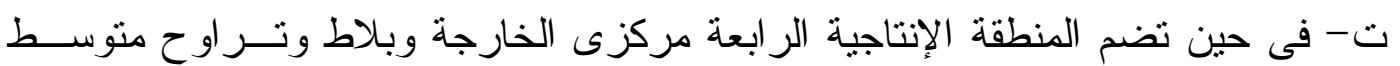

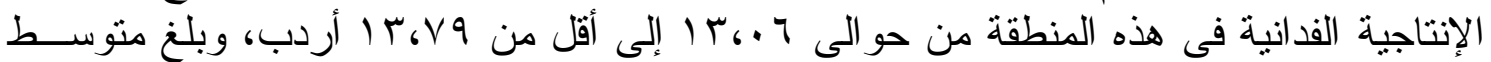

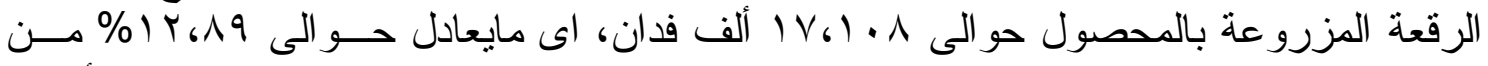

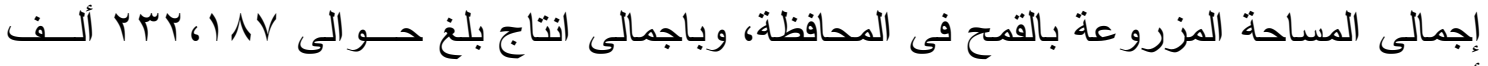

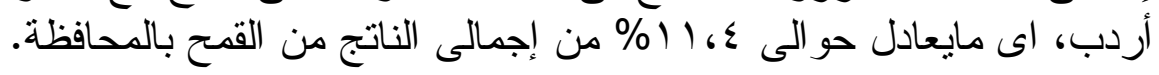

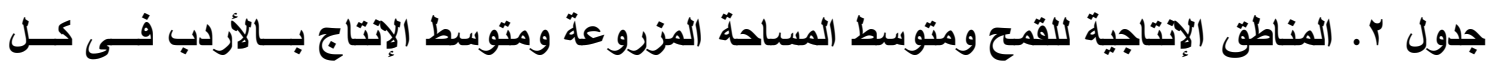

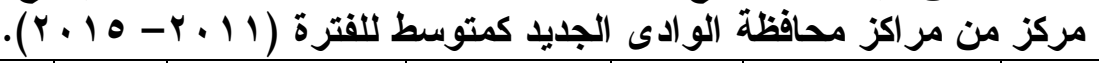

\begin{tabular}{|c|c|c|c|c|c|c|c|}
\hline$\%$ & $\begin{array}{c}\text { متوسط الإتتاج } \\
\text { (أردب) }\end{array}$ & $\%$ & متوسط المساحة & | أسماء المر اكز & المر اكز & الفئة الإتتاجية & رتبة المنطقة \\
\hline VT,TE & $1 \leqslant 9 Y \vee 9.611$ & . ، $\leqslant \varepsilon$ & $\left.940 . V_{6}\right) 1$ & |داخلة - باريس & r & $10,91-10,40$ & الأولى ل \\
\hline - & - & - & - & . & - & $10, Y 0-1$ & الثانية \\
\hline 10,47 & A & 17.71 & YrI $\leq \varepsilon$ 。. & الفر افرة & 1 & $1 \varepsilon_{6} 0 r-1 r_{6} \vee q$ & الثالثة الثة \\
\hline 1162 & YTYIAT،V & $1 r_{6} \wedge 9$ & $1 V 1 \cdot 1.07$ & | الخارجة -بلاط & r & $1 r_{6} \times 9-1 r_{6} .7$ & الر ابعة \\
\hline
\end{tabular}




\section{ب- التصنيف الإتتاجى للبصل الفتيل}

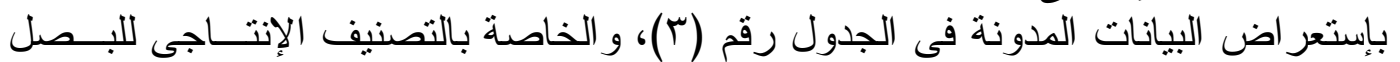

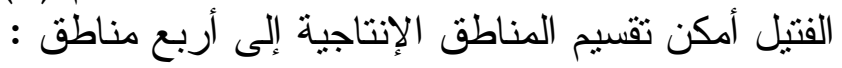

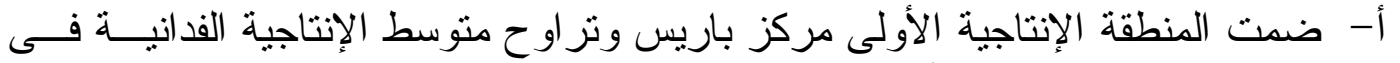

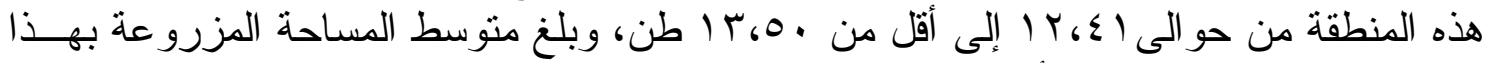

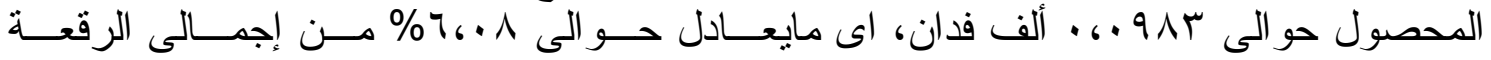

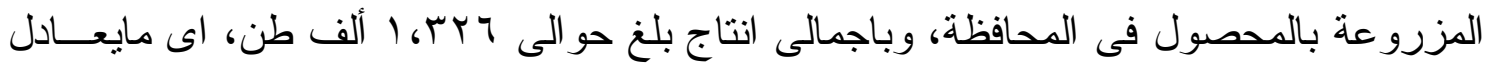

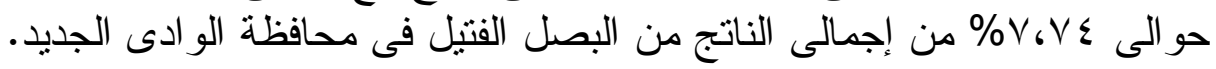

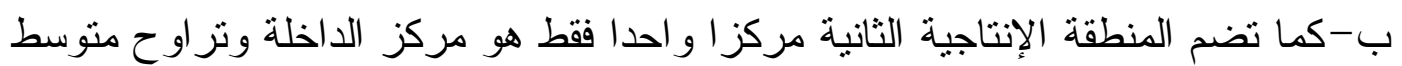

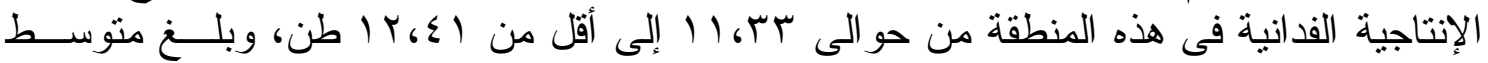

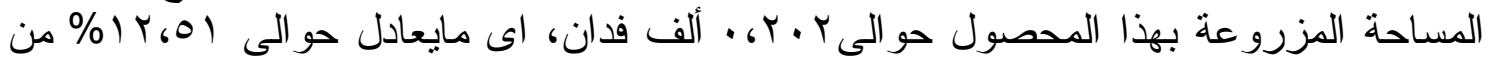

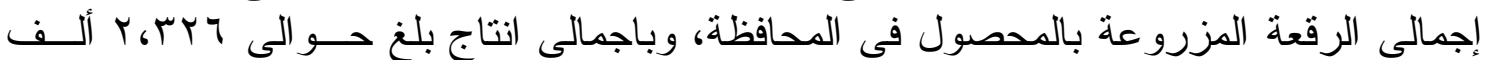

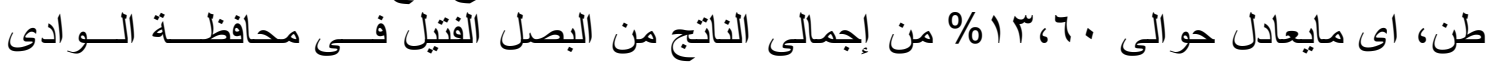

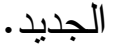

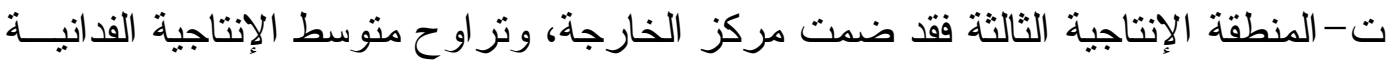

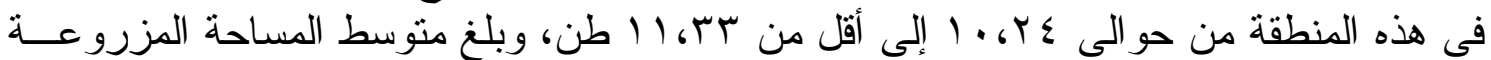

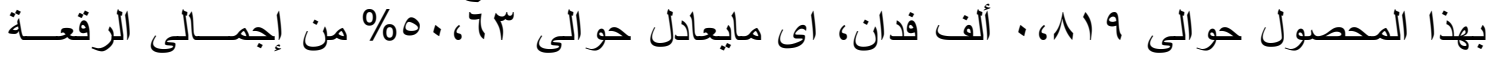

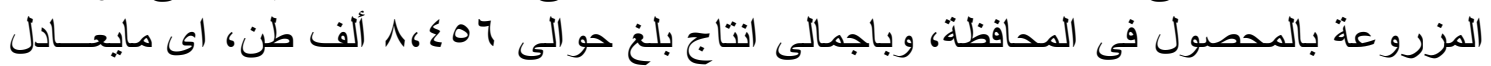

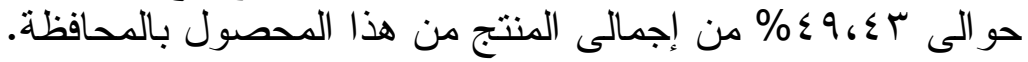

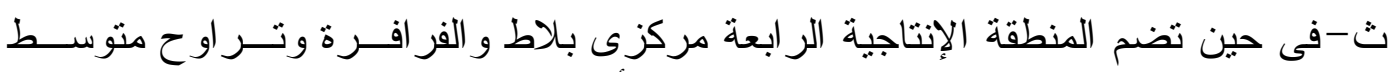

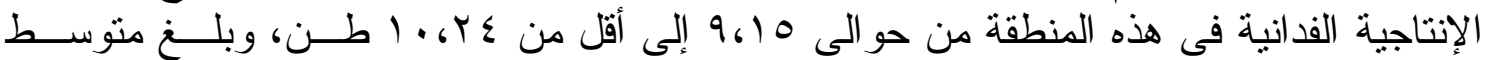

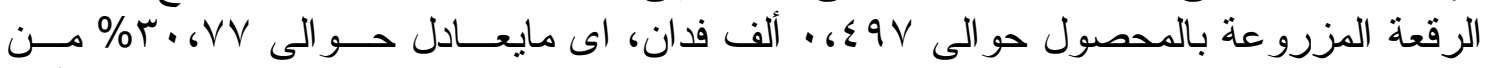

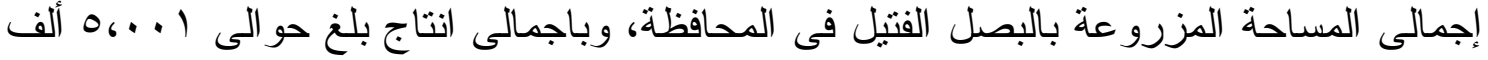

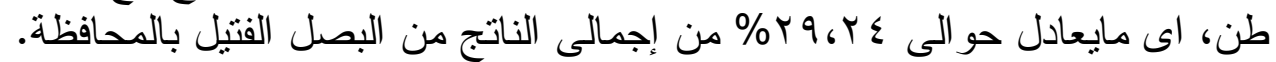

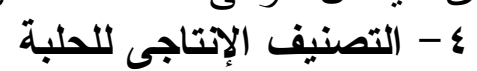

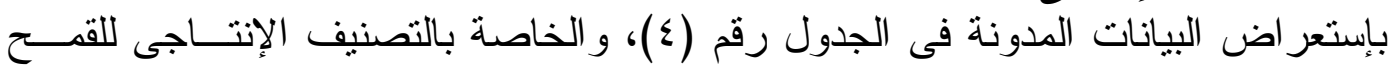

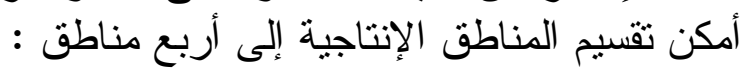

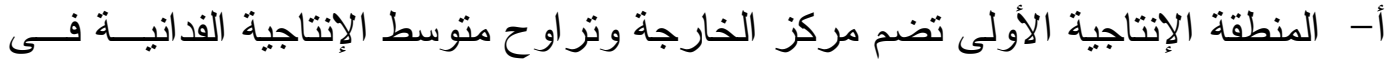

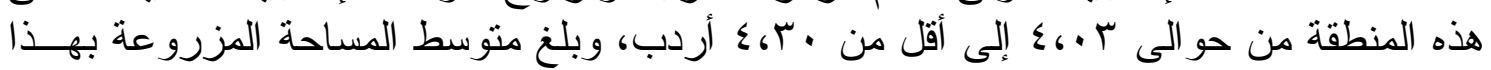

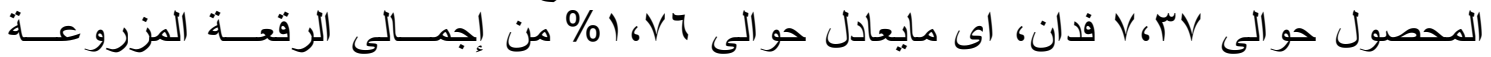

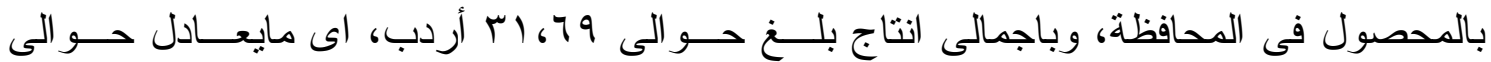
191، 19 من إجمالى الناتج من الحلبة فى محافظة الو ادى الجديد. 


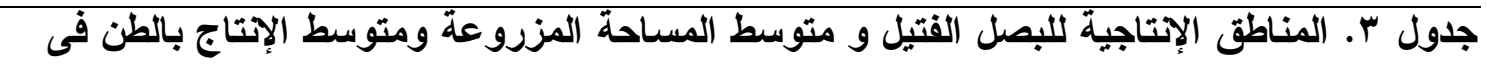

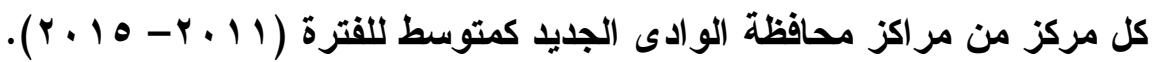

\begin{tabular}{|c|c|c|c|c|c|c|c|}
\hline$\%$ & $\begin{array}{c}\text { متوسط (طن) } \\
\text { (إانتاج }\end{array}$ & $\%$ & (فلوساحة & اسماء المر اكز & المر اكز & الفئة الإتتاجية & رتبة الإنتاجية \\
\hline$V_{6} V_{\varepsilon} \varepsilon$ & TKY & $7 . \cdot 1$ & $9 \Lambda, r Y$ & باريس & $T$ & $1 \Gamma_{6} 0 .-1 \Gamma_{6} \varepsilon 1$ & الأولى \\
\hline $1 \Gamma, 4$. & YYYO, GY & $1 Y, 01$ & T.YGKT & الداخلة & 1 & $1 K_{6} \Omega 1-11, r r$ & الثانية \\
\hline$\varepsilon 96 \leqslant r$ & $\Lambda \leqslant 006.7$ & $0.67 \pi$ & NIN,7Y & الخارجة & 1 & $11, K T-1 \cdot 64 \leq$ & الثالثة \\
\hline rq, r & $0 . \cdots 16 r \varepsilon$ & $r \cdot \sigma V V$ & $\left.\leqslant 9 V_{6} 0\right\}$ & بلاط -الفر افرة & r & $1.65 \leq-9610$ & الر ابعة \\
\hline
\end{tabular}

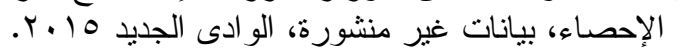

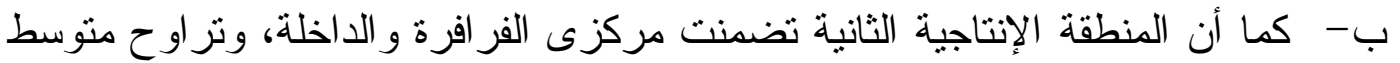

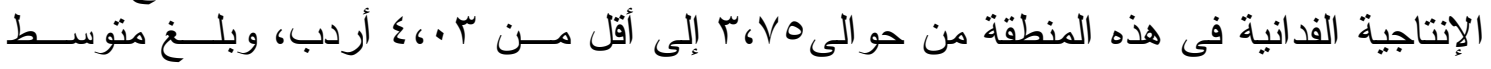

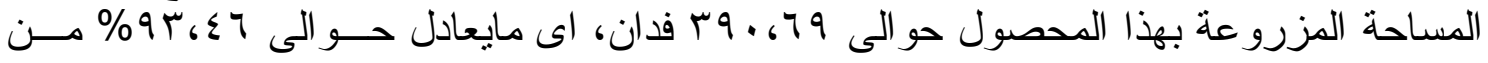

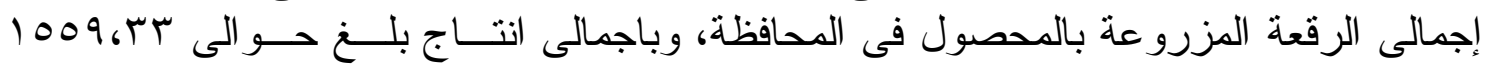

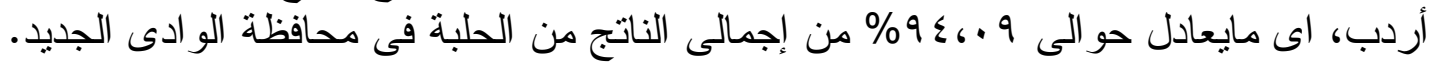

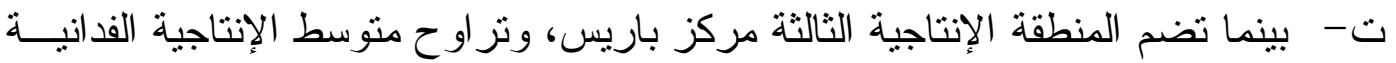

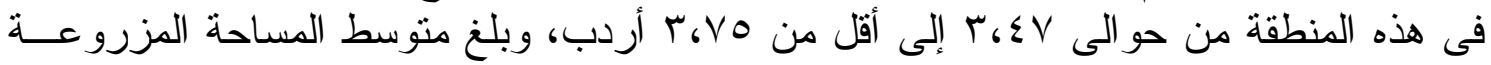

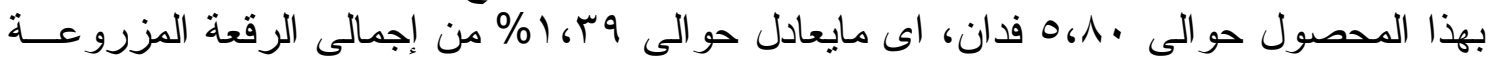

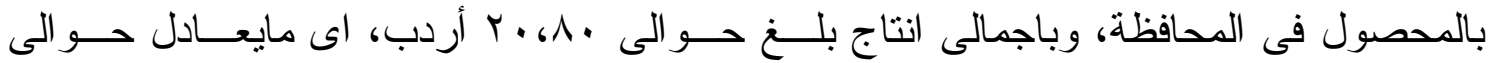

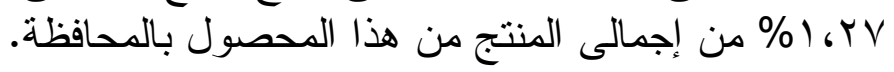

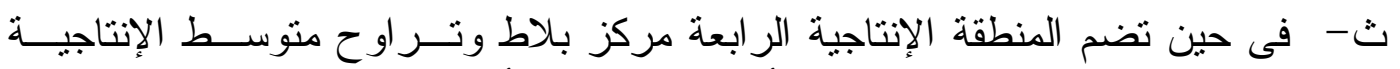

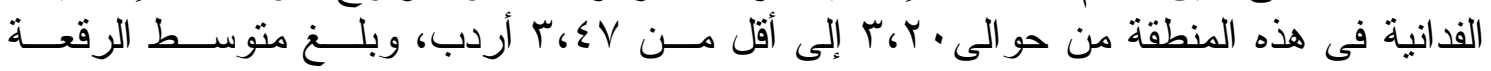

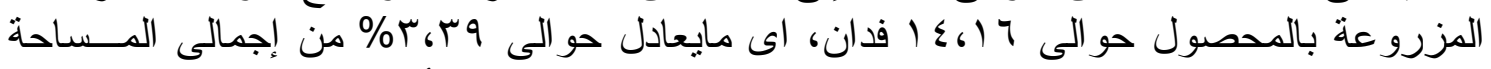

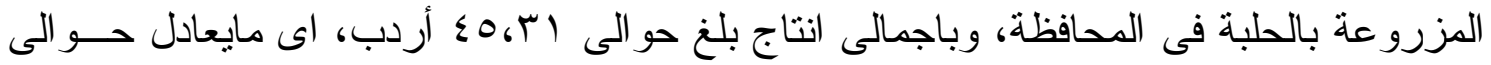
إل

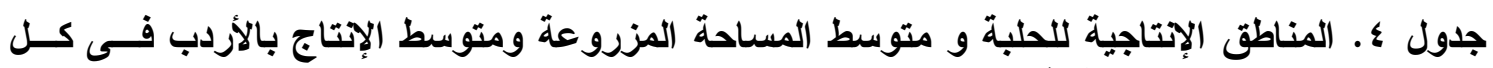

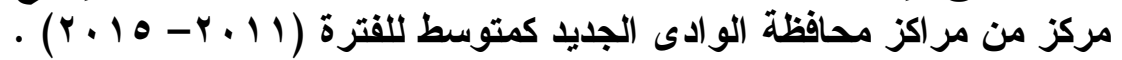

\begin{tabular}{|c|c|c|c|c|c|c|c|}
\hline$\%$ & متوسط الإتتاج & $\%$ & متوسط المساحة & اسماء المر اكز & المر اكز & الفئة الإتتاجية & الإلمنطقة \\
\hline 1.91 & 41.79 & 1.67 & $V_{6} r v$ & الخارجة & 1 & $\begin{array}{c}-\varepsilon_{6}, r \\
\varepsilon_{6} r .\end{array}$ & الأولى \\
\hline $9 \varepsilon, .9$ & $10096 \mathrm{rT}$ & $9 T_{6} \leqslant 4$ & $r 9 . .79$ & الألفرة - & r & $\begin{array}{l}-r . V_{0} \\
\varepsilon_{0 .}\end{array}$ & الثانية \\
\hline $1, \mathrm{TV}$ & $r \cdot ، \wedge$ & 1.49 & $0, \lambda$. & باريس & 1 & $\begin{array}{l}-r_{\text {r s }} \\
r_{6} v_{0}\end{array}$ & الثالثة \\
\hline r.VT & $\{0, r)$ & $r_{G} T^{\prime}$ & 15617 & بلاط بل & 1 & $r_{6} \varepsilon V-Y_{6} T$. & الر ابعة \\
\hline
\end{tabular}

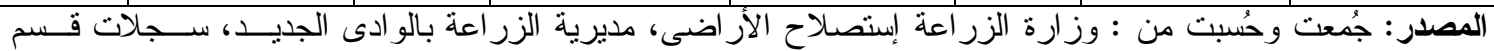

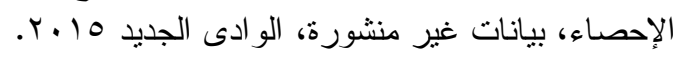




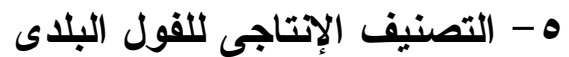

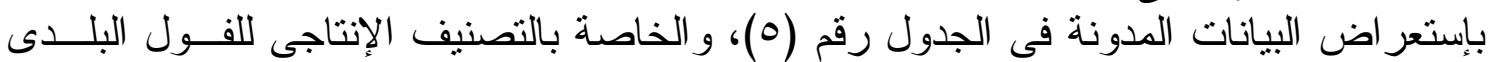
أمكن تقسيم المناطق الإنتاجية إلى أربع مناطق الإنقان

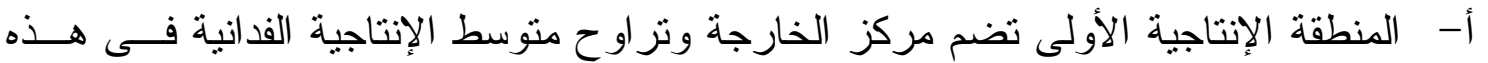

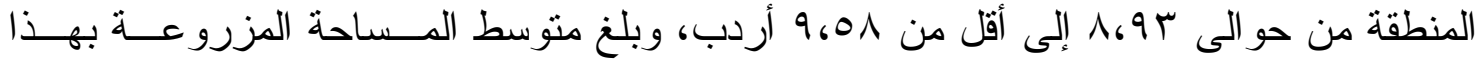

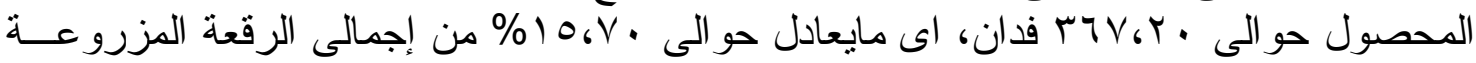

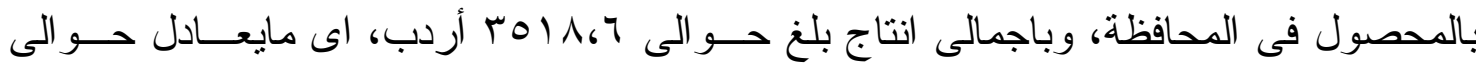

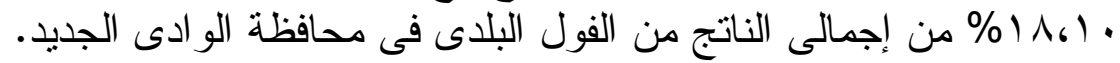

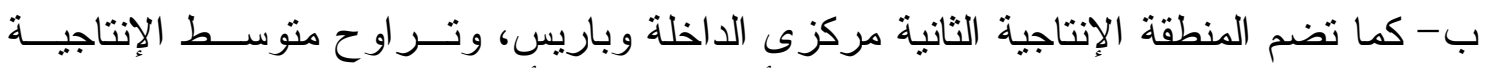

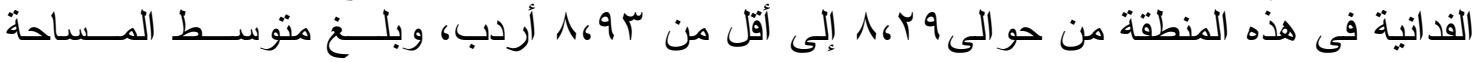

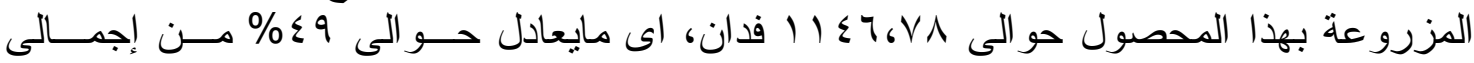

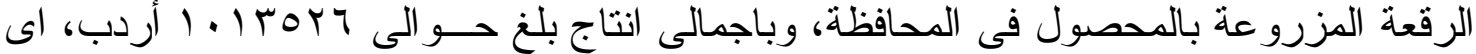

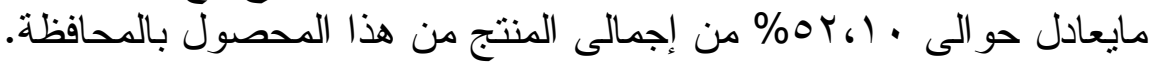

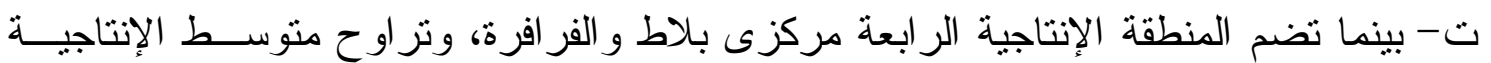

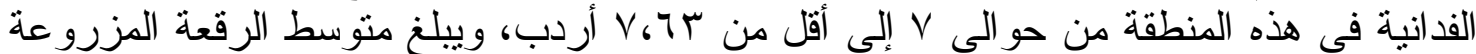

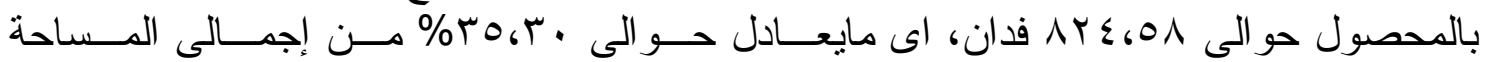

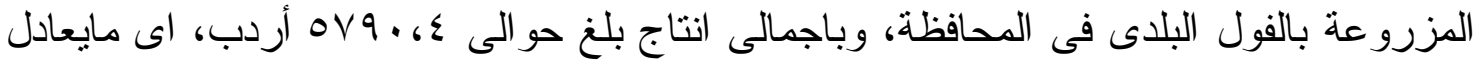

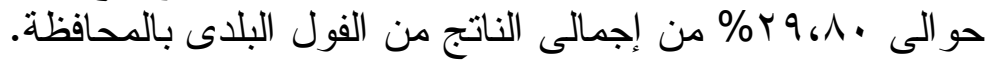

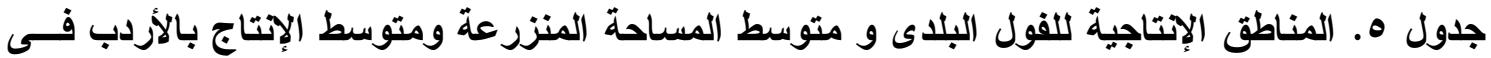

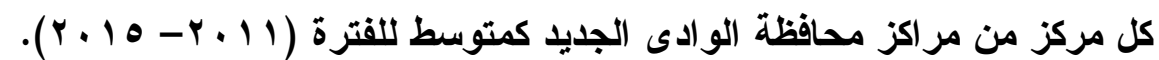

\begin{tabular}{|c|c|c|c|c|c|c|c|}
\hline$\%$ & متوسط الإتتاج & $\%$ & متوسط المساحة & اسماء المراكز & المر اكز & الفئة الإتتاجية & رتبة المنطقة \\
\hline$\left|\Lambda_{6}\right|$. & rol1.7. & $106 \mathrm{~V}$ & TTVG. & الخارجة & 1 & $9.01-1.94$ & الأولى \\
\hline OY.1. & $1.110, Y 7$ & $\sum 96 \ldots$ & $11 \leq 7, \vee \wedge$ & الداخلة وباريس & $r$ & $\Lambda_{6}, q r-\lambda_{6} r q$ & الثانية \\
\hline - & - & - & - & - & - & N.rq & الثالثة \\
\hline rq, 1. & ov9.6\&. & rogr. & $\Lambda T \varepsilon, 01$ & بلاط و الفر افرة & $r$ & V.T & الر ابعة \\
\hline
\end{tabular}

المصدر : جُمعت وحُسبت من :وزارة الزر اعة إستصلاح الأر اضى، مديرية الزر اعة بــالو ادى الجديــد، ســـلات قـسم

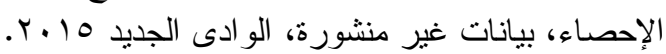

\section{4- التصنيف الإتتاجى للبصل الرووئس}

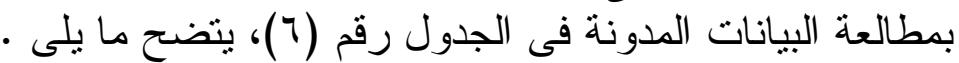

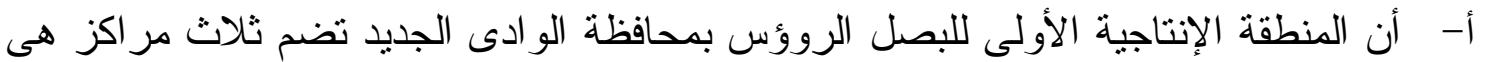

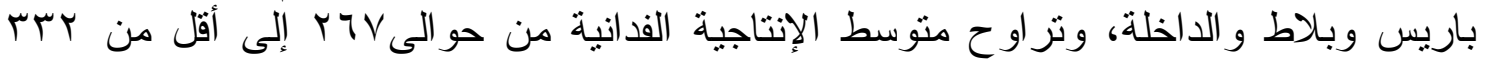

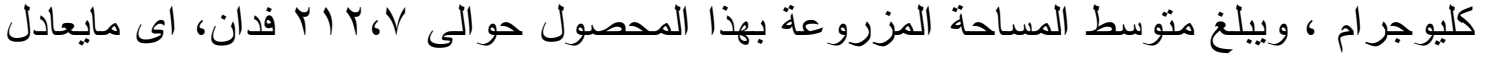

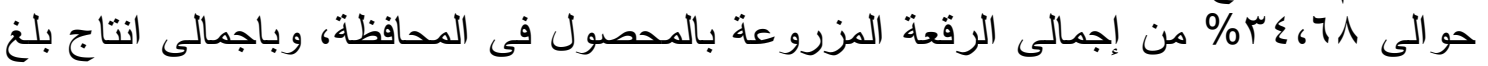




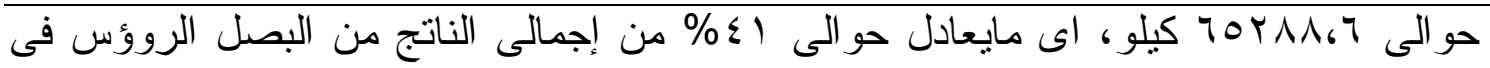
محافظة الو ادى الجديد.

ب- وتتضمن المنطقة الإنتاجية الثالثة مركز الفر افرة، وتر اوح متوسط الإنتاجية الفدانية فى هذه

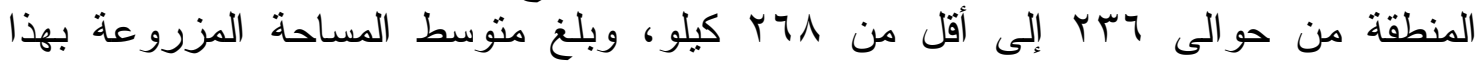

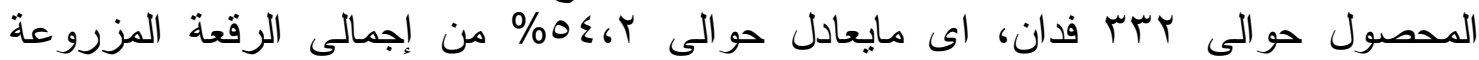

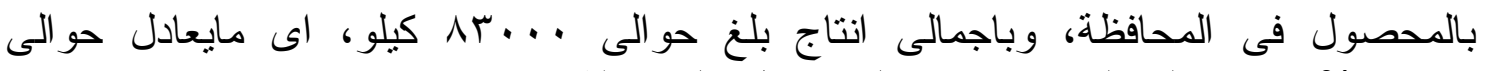

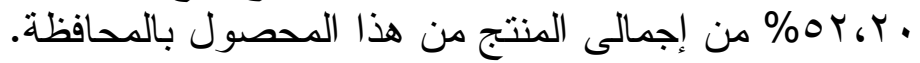

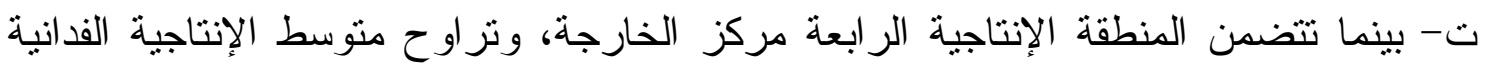

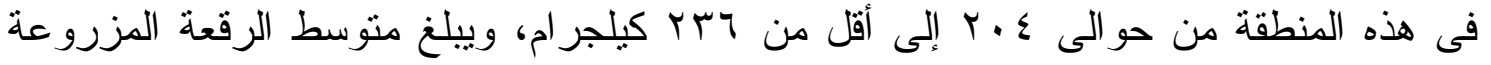

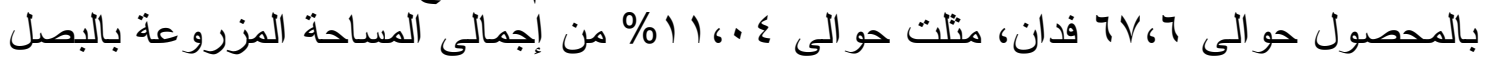

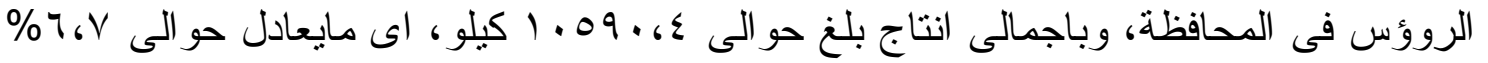
من إجمالى الناتج من البصل الروؤس بالمحافظة.

جدول 7.

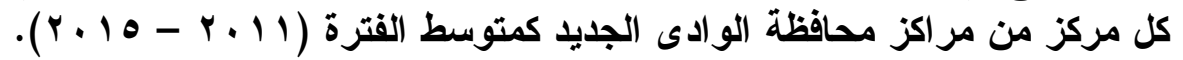

\begin{tabular}{|c|c|c|c|c|c|c|c|}
\hline$\%$ & $\begin{array}{l}\text { متوسط (لإنتاج } \\
\text { الإيلو) }\end{array}$ & $\%$ & متوسطة & اسماء المر اكز & المر اكز & 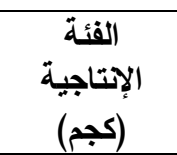 & الإلتنقة \\
\hline \&1 & 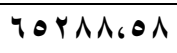 & $r \leqslant$ & YIr.V. & باريس -بلاط - الاخلة & $r$ & $r r r-r \ldots$ & الأولى \\
\hline- & - & - & - & - & - & $r \ldots-r q \Lambda$ & الثانية \\
\hline Or.r. & Ar... & $0 \leqslant 6 r$. & TrY & الفر افرة & 1 & 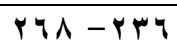 & الثالثة \\
\hline 7.8. & 1.09 .68$. & 116.8 & 78.7. & الخارجة & 1 & $r \mu q-Y \cdot \varepsilon$ & الر ابعة \\
\hline
\end{tabular}

المصدر: جُمعت وحُسبت من :وز ارة الزر اعة إستصلاح الأر اضى، مديرية الزر اعة بالو ادى الجديد، سجلات قسم

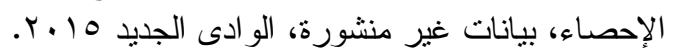

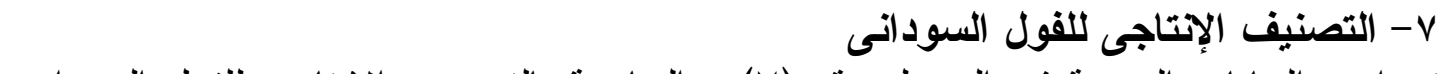

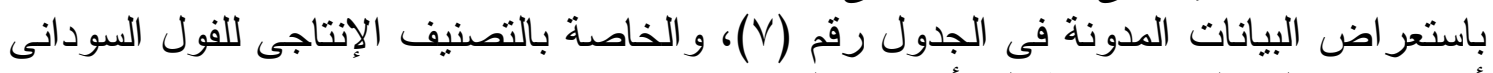

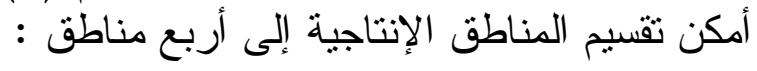

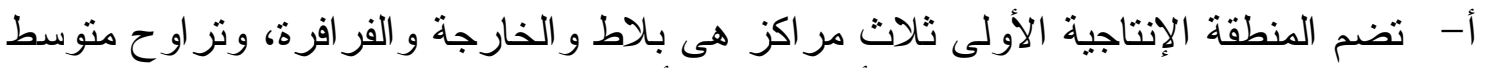

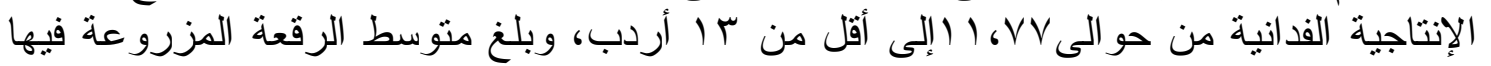

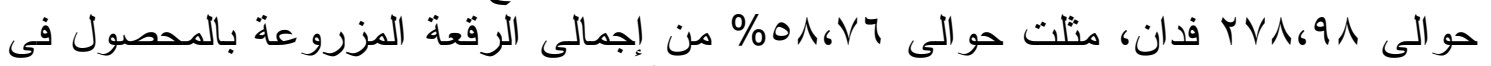

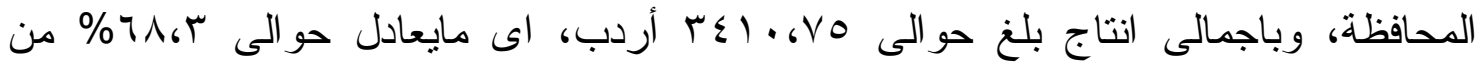
إجمالى الناتج من المحصول بالى بالمحافظة.

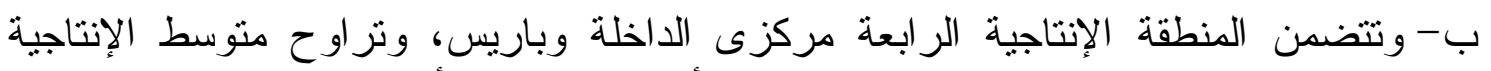

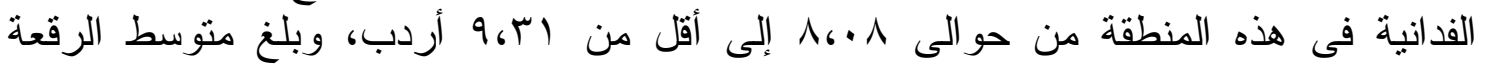

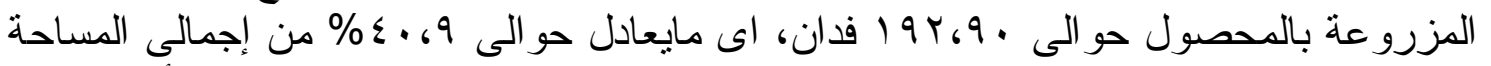

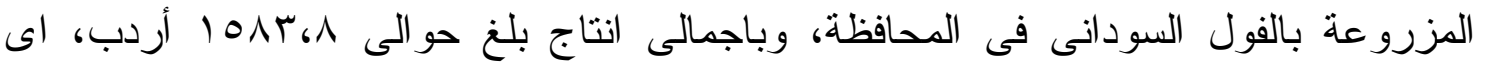

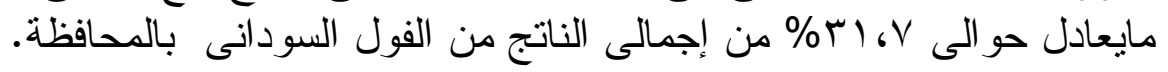




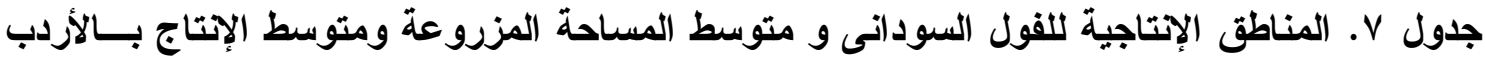

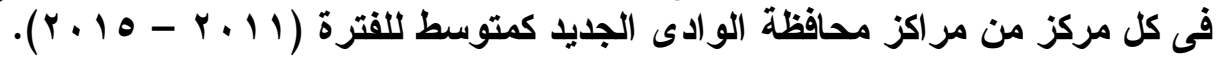

\begin{tabular}{|c|c|c|c|c|c|c|c|}
\hline$\%$ & (الإنتاج) & $\%$ & المتوسة & اسماء المر اكز & المر اكز & الفئة الإتتاجية & الإنتاجية \\
\hline TA,r. & $r \xi 1.6 v_{0}$ & $0 \Lambda_{6} V 4$ & rVA.9A & بلاط - الخارجة - الفر افرة & $r$ & $1 T-116 \mathrm{VV}$ & 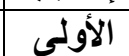 \\
\hline- & - & - & - & - & - & $11.6 V-1.60 \varepsilon$ & الثانية \\
\hline- & - & 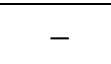 & - & - & - & $1.60 \leqslant-9,41$ & الثالثة \\
\hline I. V. & $0 \wedge r_{\Delta} \Delta$. & $\varepsilon .69$. & 194.9. & الداخلة - باريس & r & $\left.q_{6} \mu^{\prime}\right)-\lambda_{6} \cdot \Lambda$ & رابعة \\
\hline
\end{tabular}

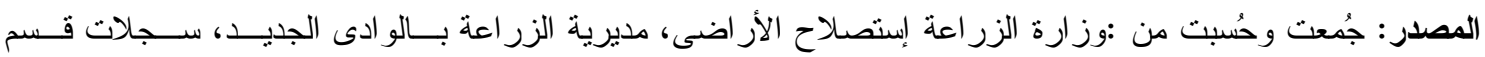

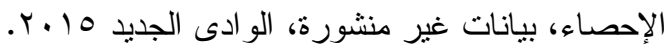

\section{1- 1 التصنيف الإنتاجى للسمسم

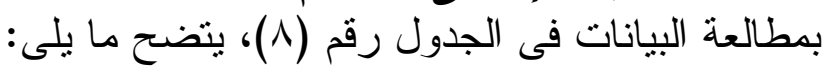

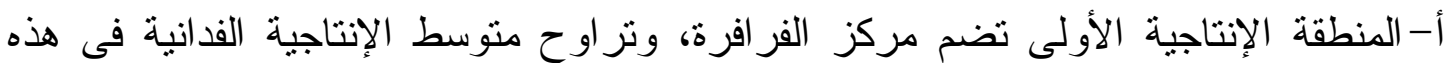

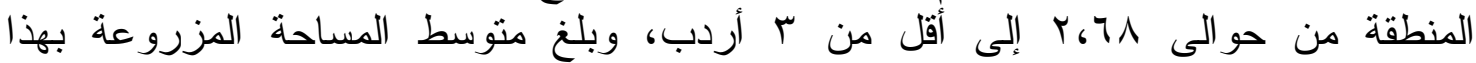

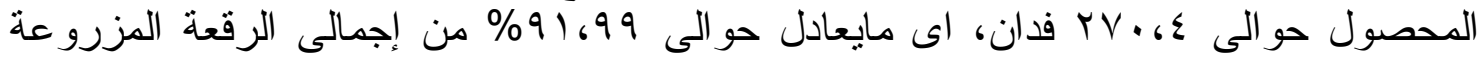

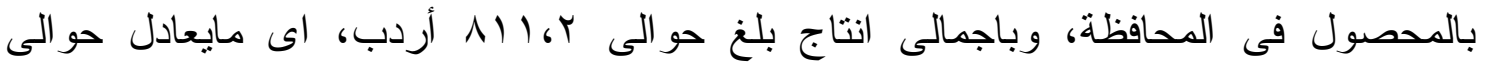

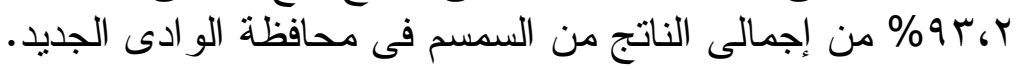

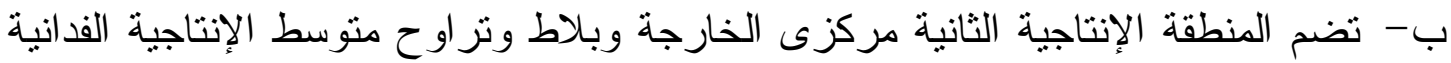

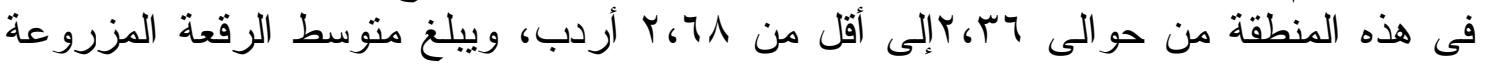

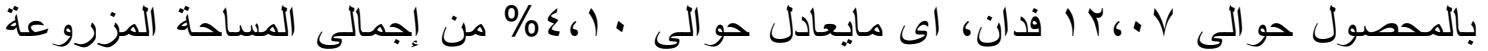

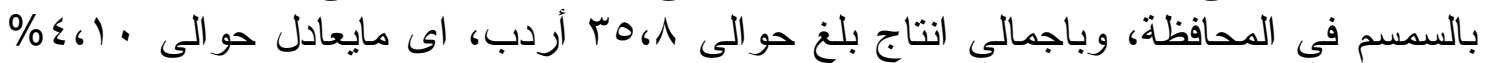
من إجمالى الناتج من السمسم بالمحافظة.

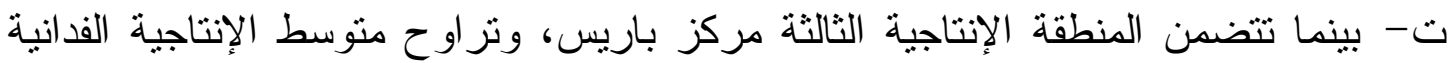

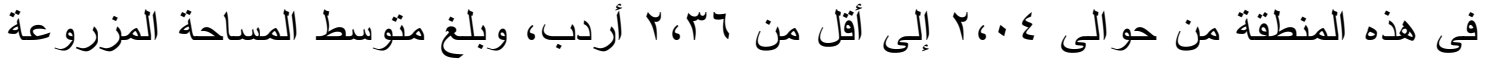

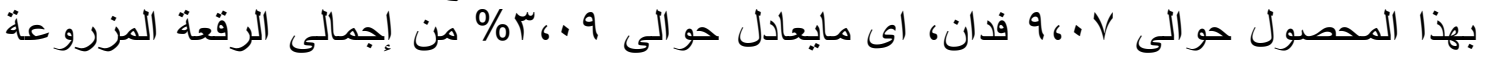

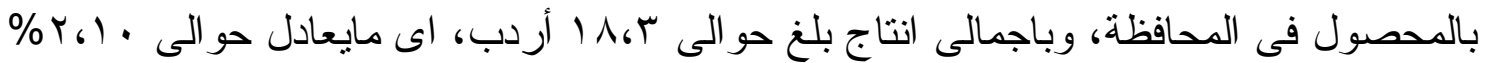

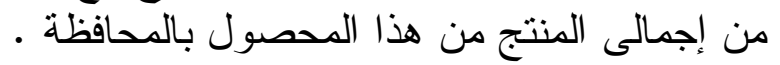

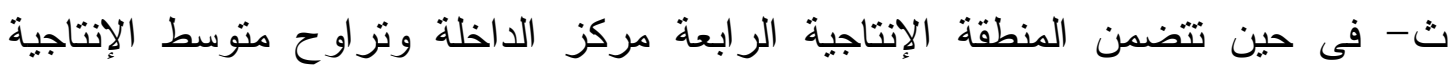

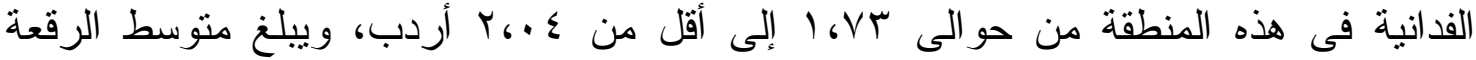

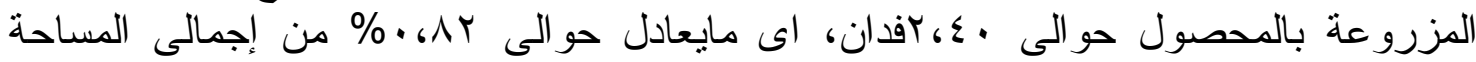

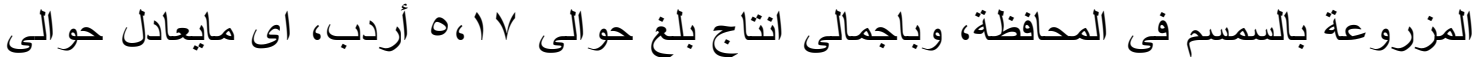
09، • \% من إجمالى الناتج من السمسم بالمحافظة . 


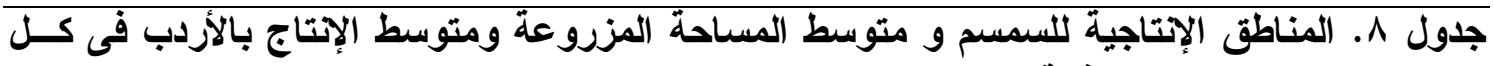

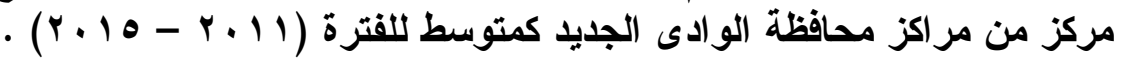

\begin{tabular}{|c|c|c|c|c|c|c|c|}
\hline$\%$ & متوسط الإنتاج) & $\%$ & متوسطة & اسماء المر اكز & المر اكز & 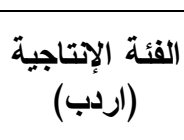 & رتبة الإنتاجية \\
\hline QT, T. & NII. . & 91.99 & $r V \cdot \sigma \varepsilon$. & الفر افرة & 1 & $r-r_{6}, \uparrow \Lambda$ & الأولى \\
\hline$\left.\varepsilon_{6}\right)$. & $r 0_{0} \wedge$. & $\left.\varepsilon_{6}\right)$. & $T_{6} T_{0}$ & الخارجة - بلاط & T & 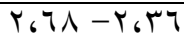 & الثاتية \\
\hline$\left.r_{6}\right)$. & $1 A_{6} r$. & $r_{6} .9$ & $q_{6} \cdot V$ & باريس & 1 & $r_{6} r_{7}-r_{6} \cdot \varepsilon$ & الثالثة \\
\hline .609 & $0,1 \mathrm{~V}$ & . ‘AY & Y.\&. & الداخلة & 1 & $T_{6} \cdot \varepsilon-1_{6} V T$ & الر ابعةٌة \\
\hline
\end{tabular}

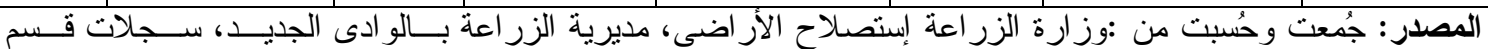

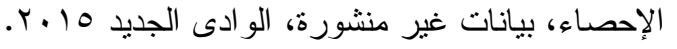

\section{9- التصنيف الإتتاجي للبرسيم الحجازى (9) الجيان}

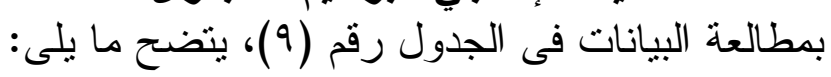

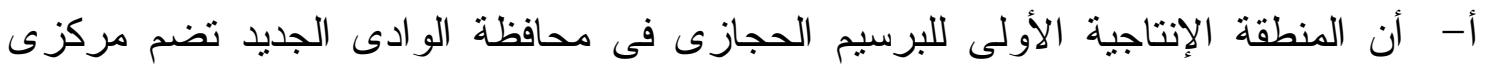

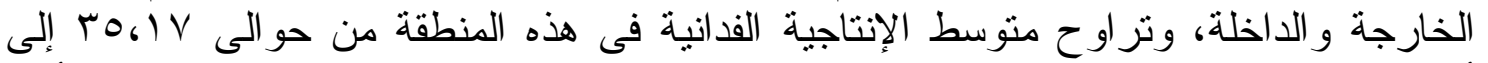

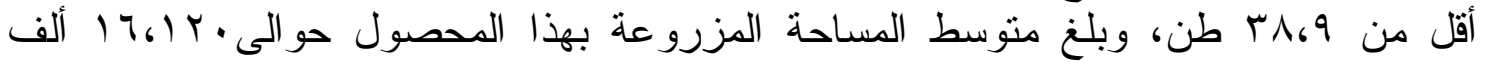

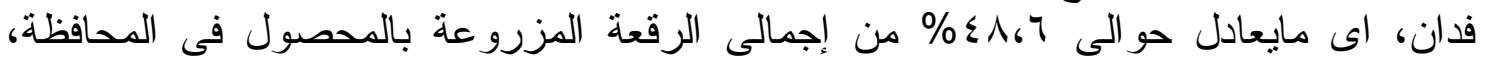

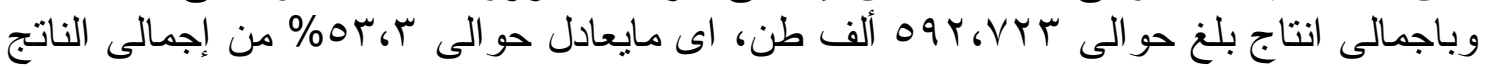

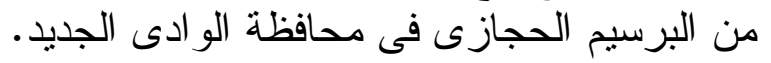

ب- وتتضمن المنطقة الإنتاجية الثانية مركزى باريس و الفرافرة، وتز اوح منوسط الإنتاجية

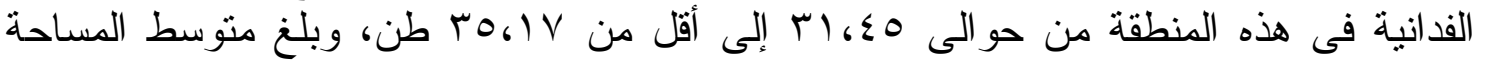

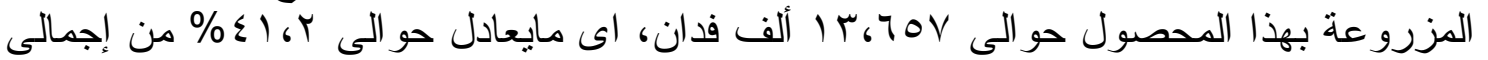

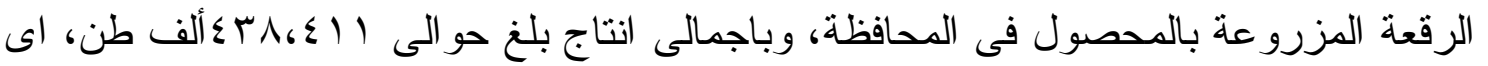

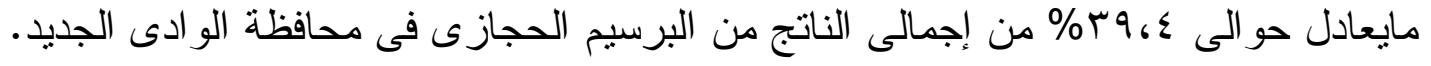

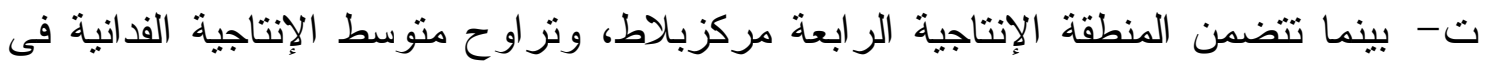

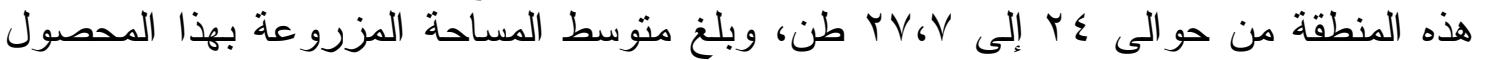

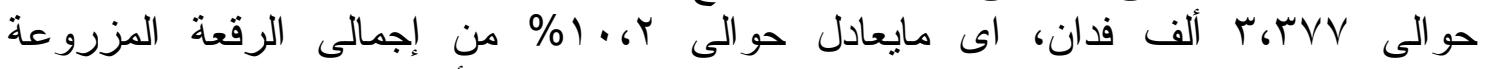

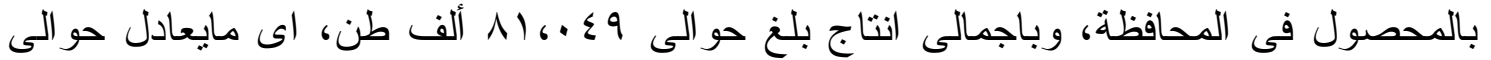

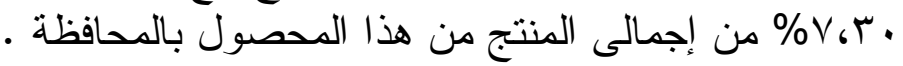

جدول 9. المناطق الإتتاجية بالبرسيم الحجازى و متوسط المساحة المزروعة ومتوسط الإنس الإتتاج بالطن

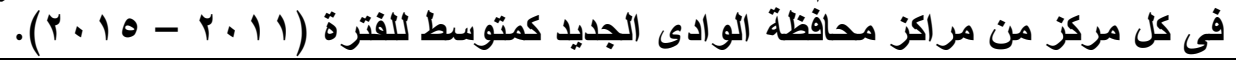

\begin{tabular}{|c|c|c|c|c|c|c|c|}
\hline$\%$ & متوسط الإنتاج & $\%$ & متوسط & اسماء المر اكز & المر اكز & الفئة الإتتاجية & الإنتاجية \\
\hline Or.r. & OQTVYTGT. & $\leqslant \Lambda_{6} 7$. & 17119697 & الخارجة - الداخلة & $r$ & $\left.r_{\Lambda_{6}} q .-r_{0}\right) \mathrm{V}$ & الأولى \\
\hline$r_{q} \varepsilon \varepsilon$. & $\varepsilon r \wedge \varepsilon \|$ & $\varepsilon 1,4$. & 17707.7. & باريس - الفرة & $r$ & $\left.\Gamma_{0}\right) V-\Gamma_{1} \leqslant 0$ & الثانية \\
\hline- & - & - & - & - & - & $r_{1} \leqslant 0-r V_{6} V$ & الثالثة \\
\hline$V_{6} r$ & $11 \cdot \leq 96 \leqslant \leqslant$ & $1.6 \%$. & rrVV.l. & بلاط & 1 & $Y V_{6} V-Y \leq$ & الر ابعة \\
\hline
\end{tabular}

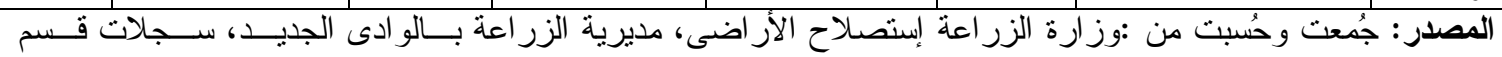

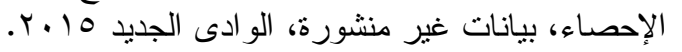


.

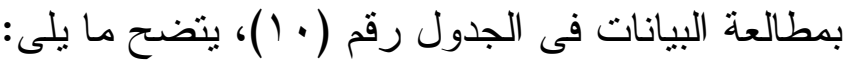

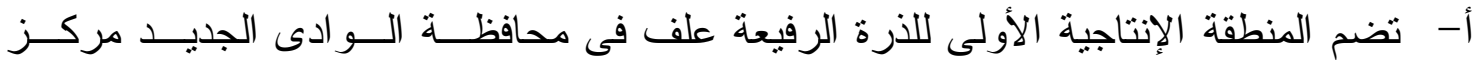

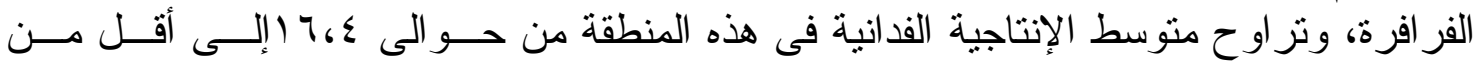

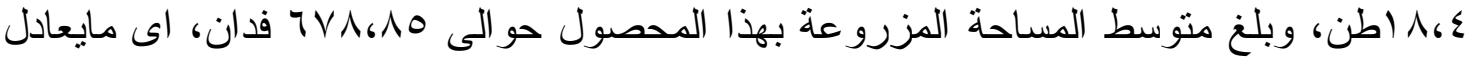

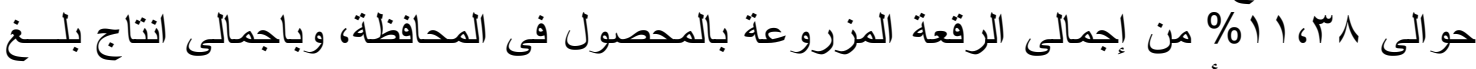

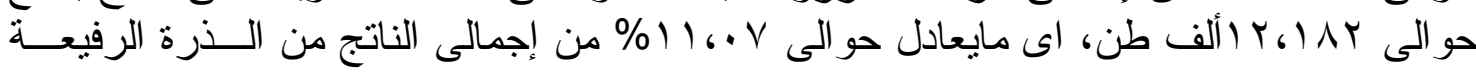
علف فى محافظة الو ادى الجديد.

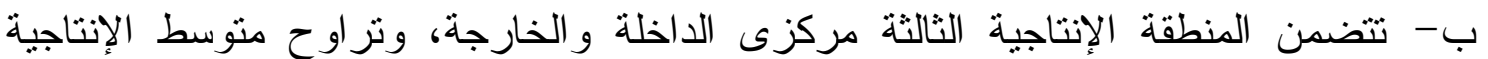

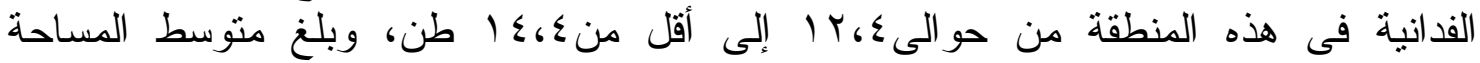

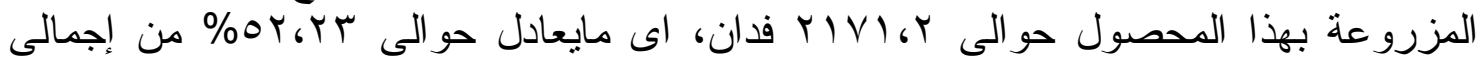

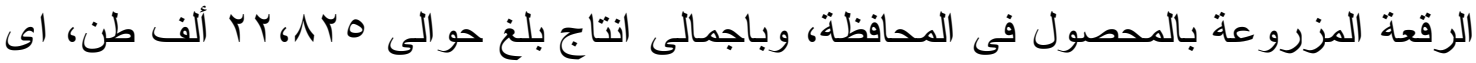

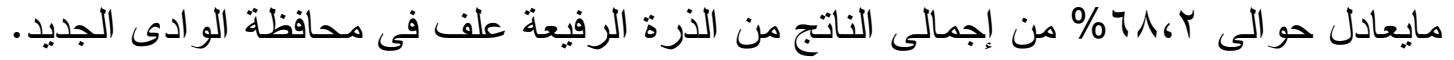

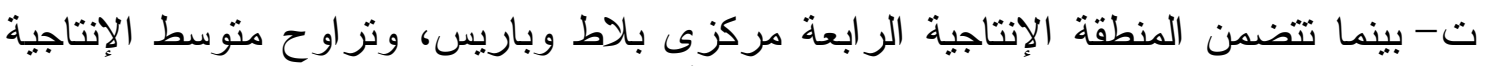

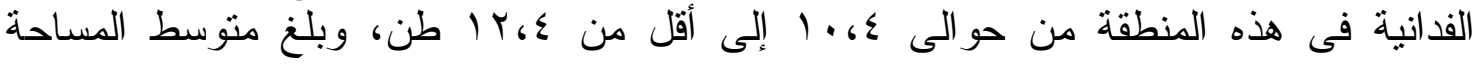

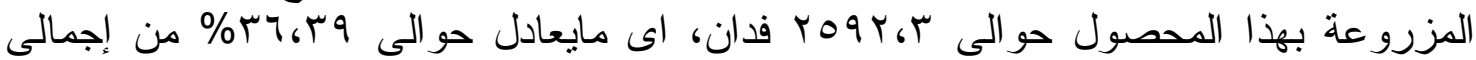

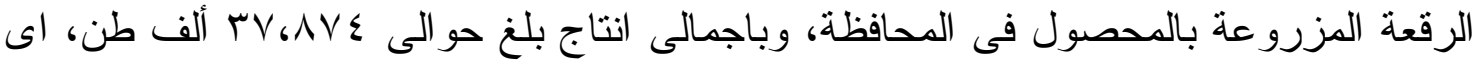

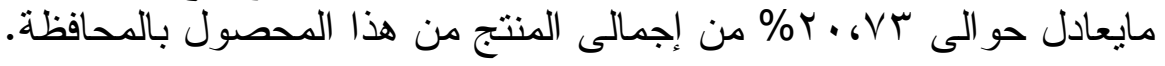

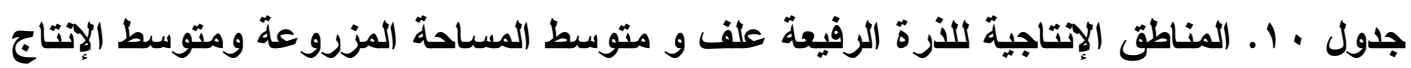

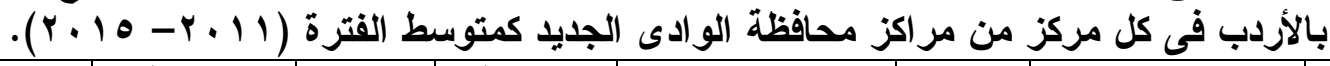

\begin{tabular}{|c|c|c|c|c|c|c|c|}
\hline$\%$ & $\begin{array}{l}\text { متتوسط } \\
\text { (طن) }\end{array}$ & $\%$ & 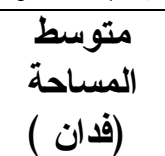 & اسماء المر اكز & المر اكز & الفئة الإتتاجية & المنتطة \\
\hline $11, .0 \mathrm{~V}$ & IYINI,A. & $11,4 \mathrm{r}$ & $T \vee \wedge_{6} \wedge_{0}$ & الفر افرة & 1 & $11_{6} \varepsilon \cdot-1 T_{6} \varepsilon=$ & الأولى \\
\hline- & - & - & - & - & - & $17_{6} \varepsilon_{0}-1 \varepsilon_{6} \varepsilon_{0}$ & الثانية \\
\hline TA, Y. & TYAYO,. & OYGYT & TIVIGT. & الداخلة - الخارجة & $r$ & $\left|\varepsilon_{6} \varepsilon_{0}-\right| Y_{6} \varepsilon_{0}$ & الثالثة \\
\hline T.6VT & TVAVT,qY & r4.rq & TO9YGTO & بلاط - باريس & $r$ & 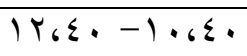 & الر ابعة \\
\hline
\end{tabular}

\section{1- التصنيف الإتتاجى للكمون}

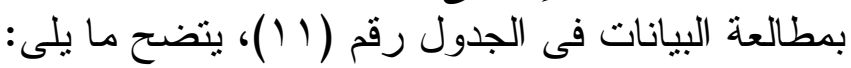

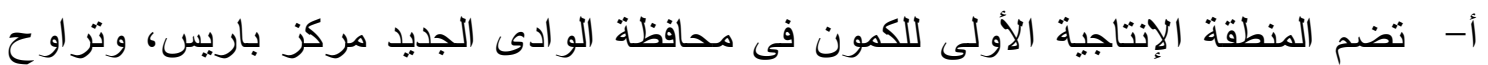

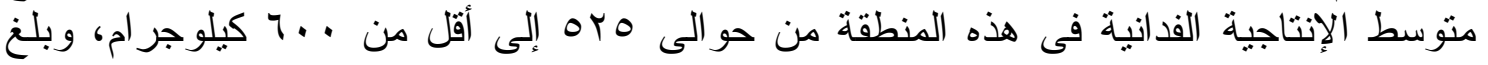

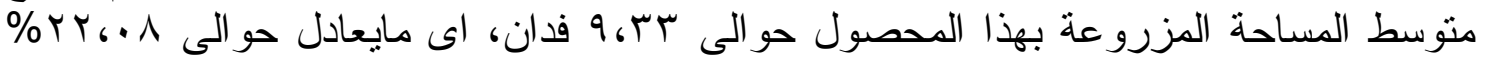

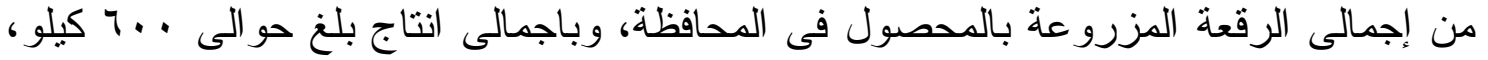

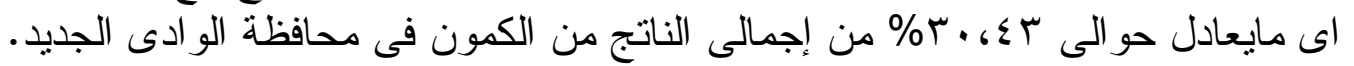

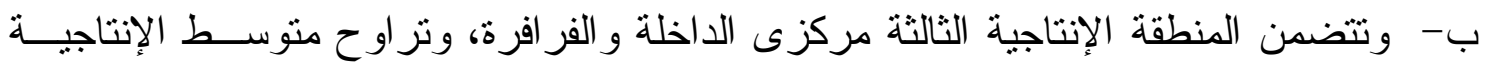

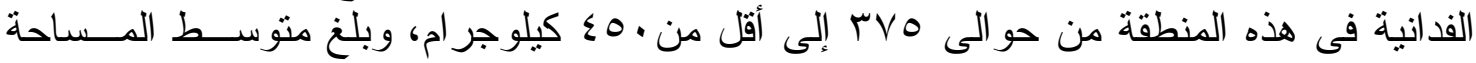




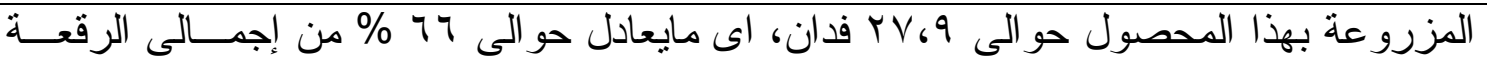

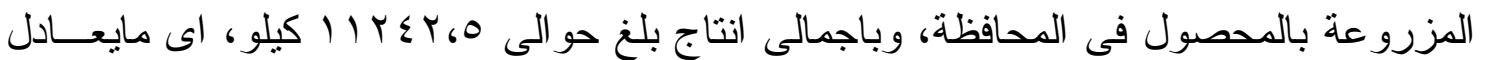

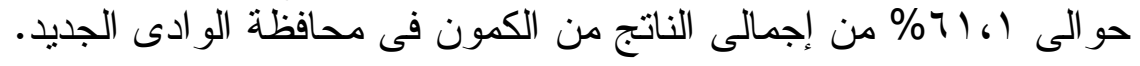

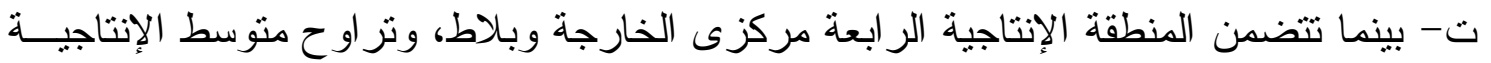

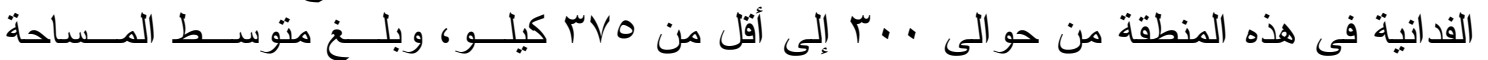

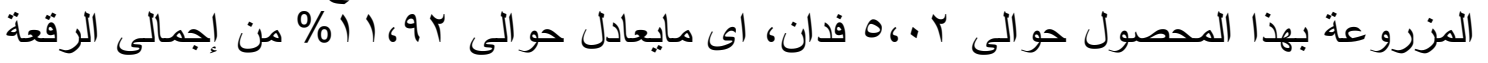

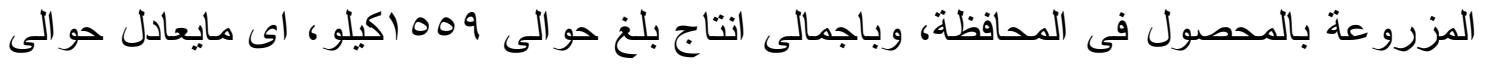

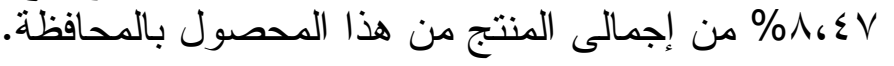

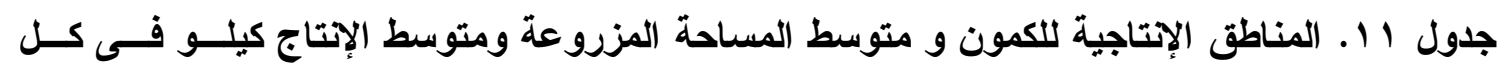

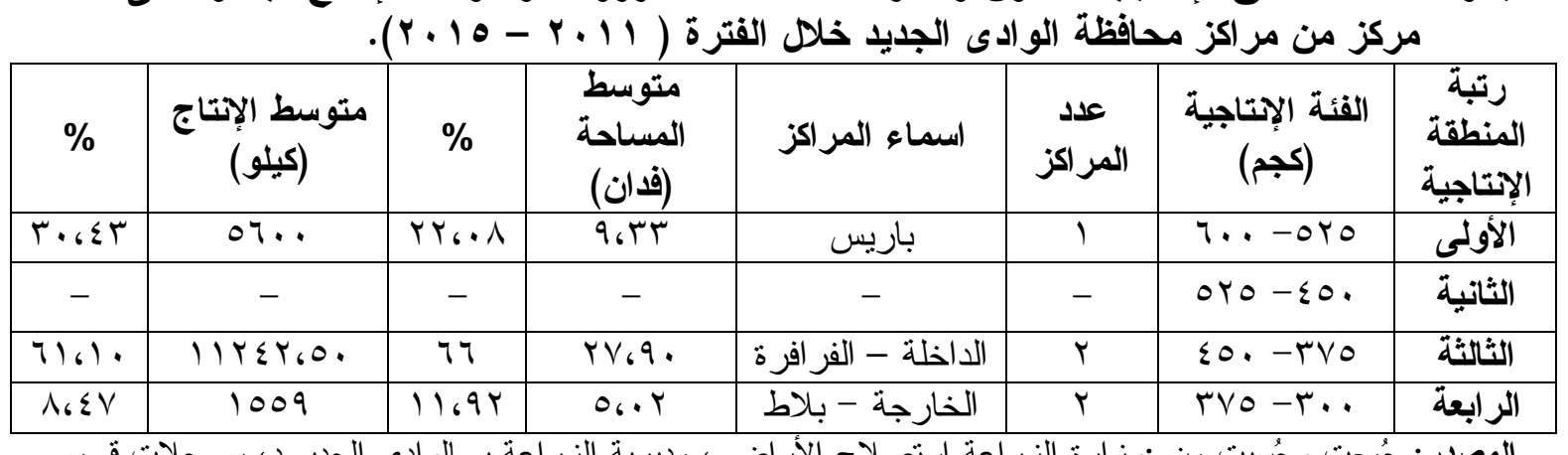

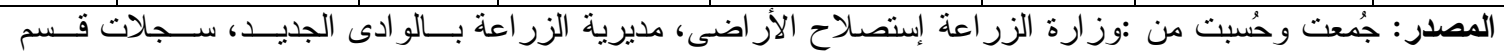

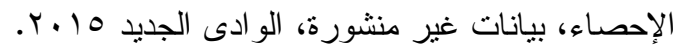

ثانيا: تصنيف أراضى محافظة الوادى الجديد وفقا للجدارة الإنتاجية لإجمالى الزروع العيد الحقلية الرئيسية

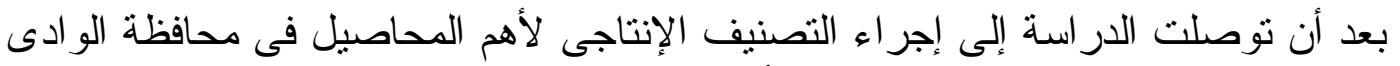

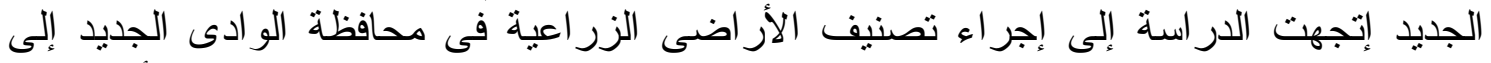

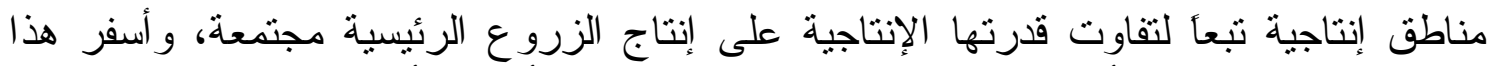

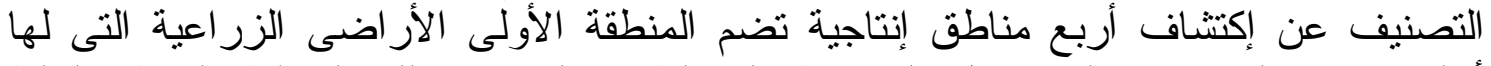

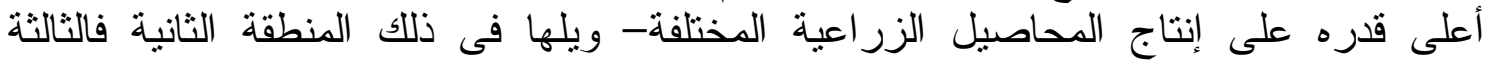

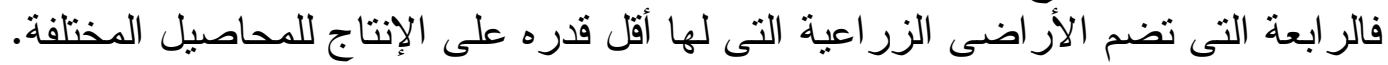

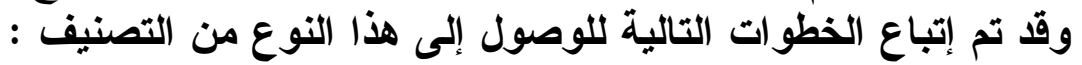

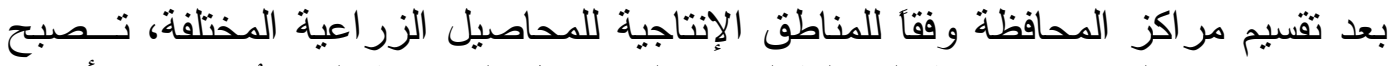

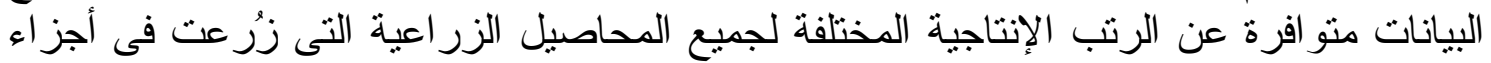

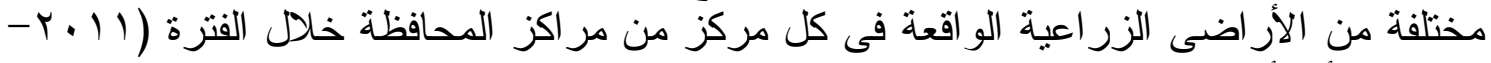

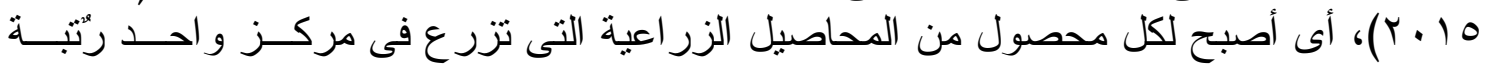

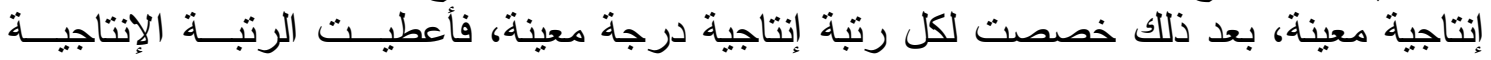

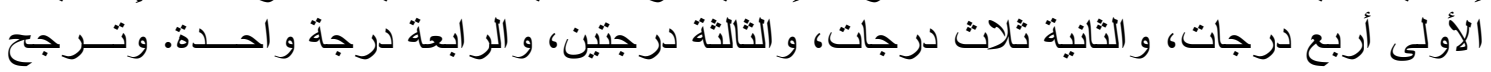

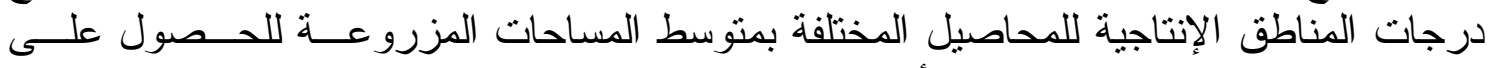

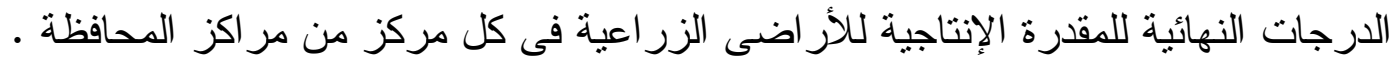

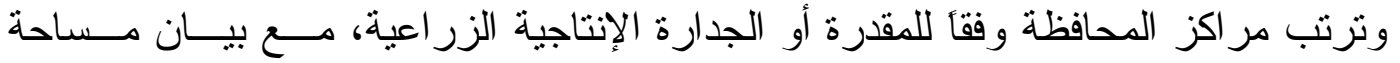

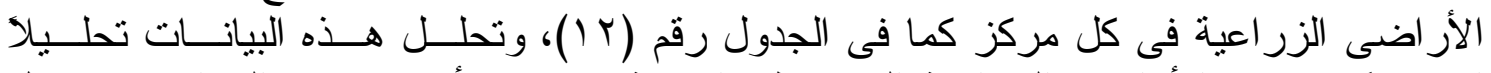

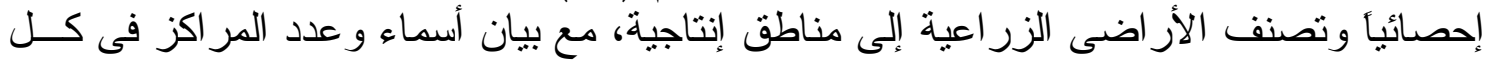




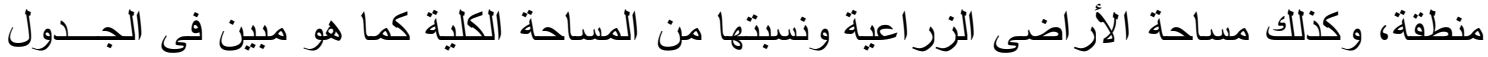

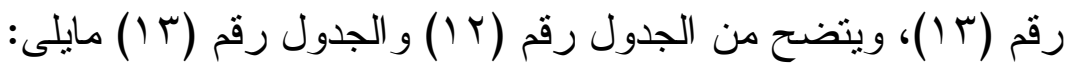

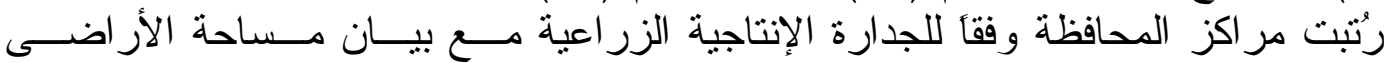

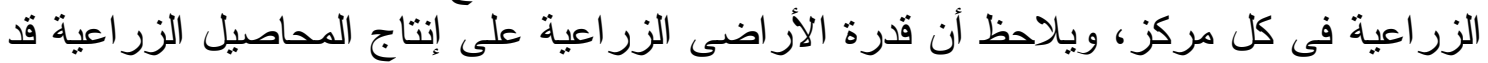

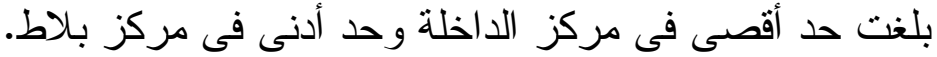

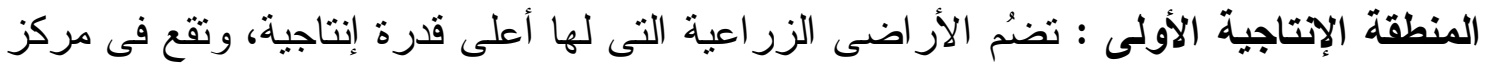

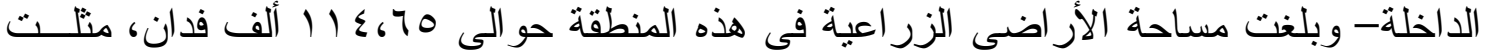

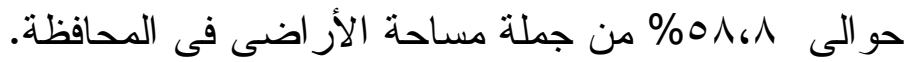

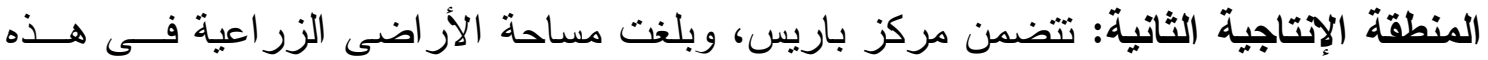

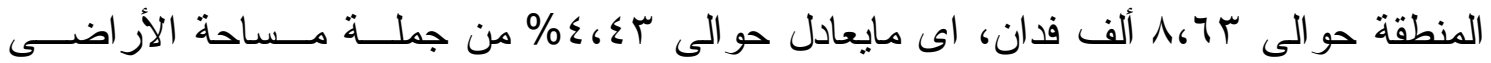
الزمنة اعية في المحافظة.

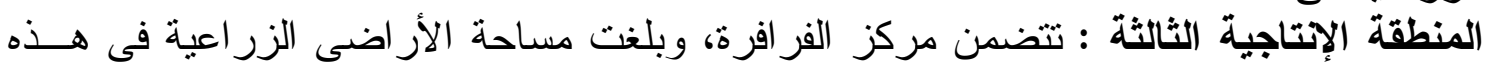

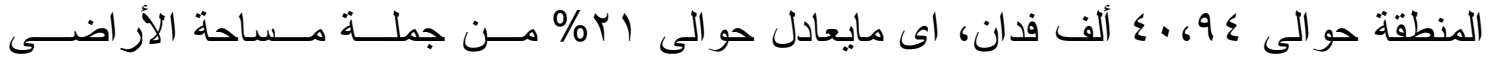
الزمر اعية في المحافظة.

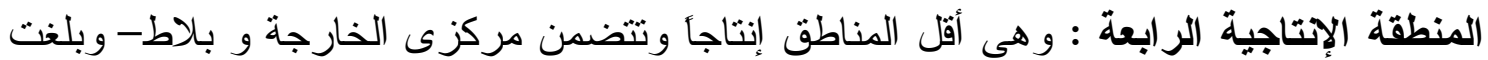

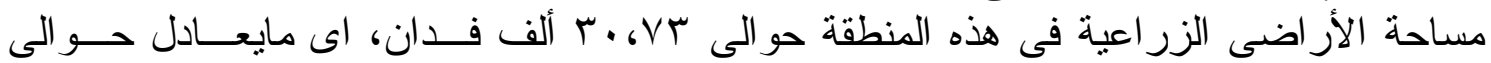

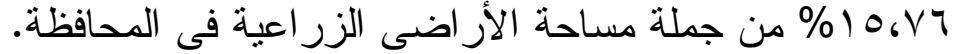

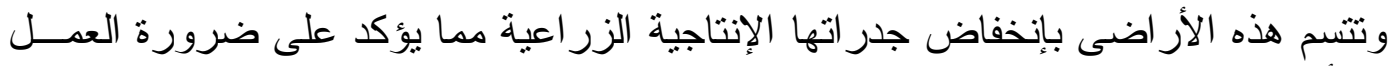

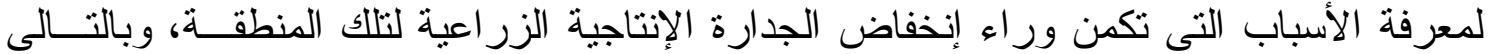

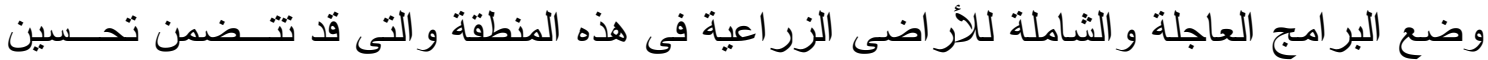

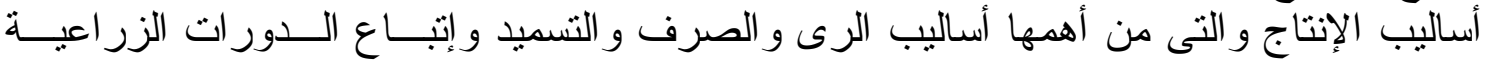
المناسبة.

جدول r ا. ترتيب مراكز محافظة الوادى الجديد وفقاً للجدارة الإتتاجية الزراعية كمتوسط الفترة ( 11 . ب -

\begin{tabular}{|c|c|c|c|}
\hline & & \multicolumn{2}{|c|}{.$(r \cdot 10$} \\
\hline مساحة الإراضى الزراعية بألف فدان & الجدارة الإتتاجية & الرتبة الإنتاجية & المر اكز \\
\hline $11 \leqslant 670$ & $r .90$ & 1 & الا اخلة \\
\hline$\Lambda_{6} 74$ & $r_{6} \cdot r$ & $r$ & باريس \\
\hline$\varepsilon \cdot .9 \varepsilon$ & Y.YT & $\mu$ & الفر افزة \\
\hline Y1, & $1.7 \varepsilon$ & $\varepsilon$ & الخارجة \\
\hline 9.74 & 16.9 & 0 & بلاط \\
\hline
\end{tabular}

المصدر: جُمعت وحُسبت من :وز ارة الزر اعة إستصلاح الأراضى، مديرية الزر اعة بالو ادى الجديد، سجلات قسم

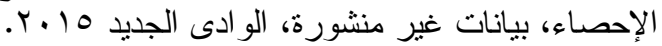

جدول ب ا ـ تصنيف الأراضى الزراعية فى محافظة الوادى الجديد إلى مناطق إنتاجية خلال الفتــرة (11 ـ ץ-

\begin{tabular}{|c|c|c|c|c|c|}
\hline$\%$ & متوسط المساحة & أسماء المر اكز & المر اكز & الفئة الإنتاجية & رتبة المنطقة \\
\hline$\Delta \Lambda_{6} \wedge$ & $11 \leqslant 670$ & الداخلة & 1 & r.90_r.T. & الأولى \\
\hline$\varepsilon$ \& $\varepsilon r$ & $\Lambda_{6} 74$ & باريس & 1 & r.Y. - Y,YT & الثانية \\
\hline YI & $\varepsilon .69 \varepsilon$ & الفر افرة & 1 & Y.Y7_I6VO & الثالثة \\
\hline $10 . V 7$ & $r \cdot \sigma V r$ & بلاط - الخارجة & r & $16 V 0_{-} 16.4$ & الرابعة \\
\hline
\end{tabular}

المصدر : حسبت من الجدول رقم (r ()). 


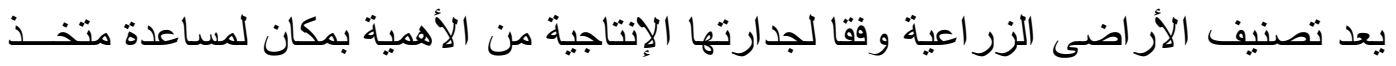

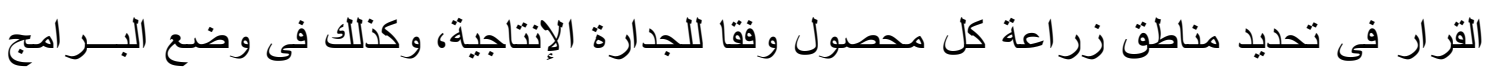

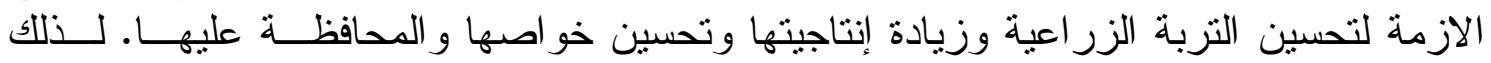

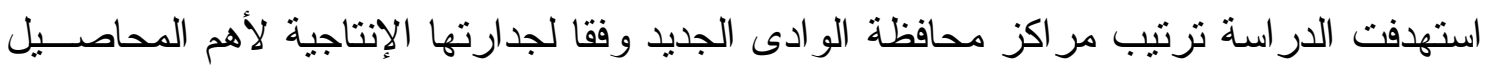

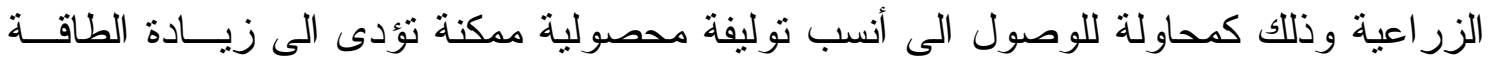
و الجدارة الإنتاجية لتلك المحاصيل.

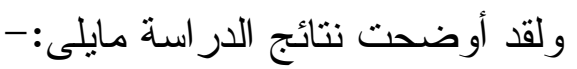

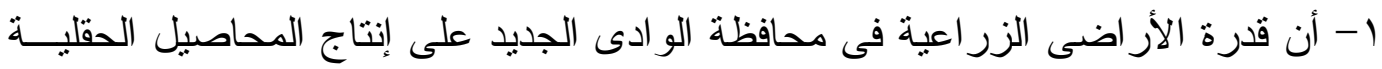

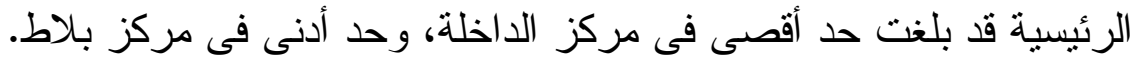

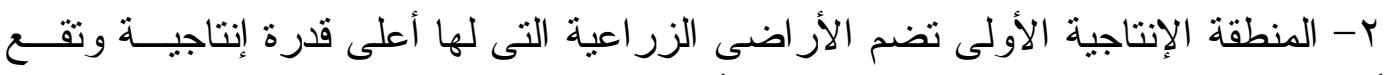

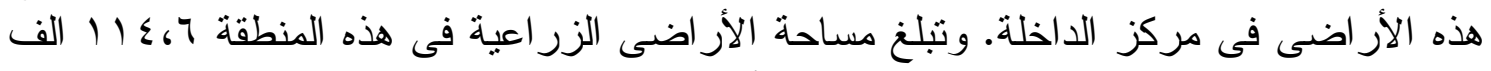

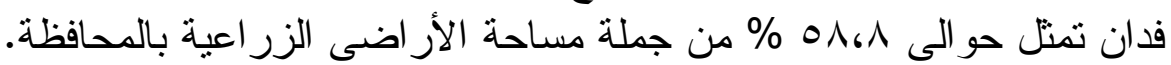

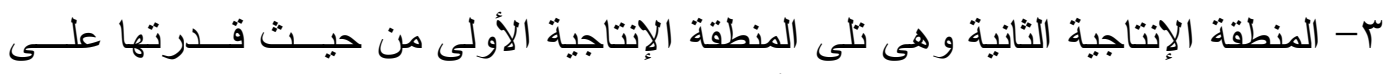

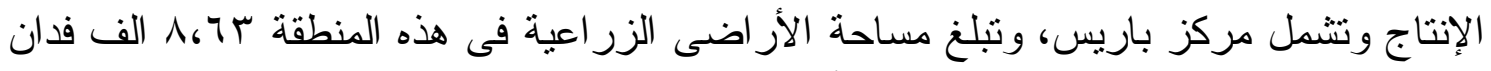

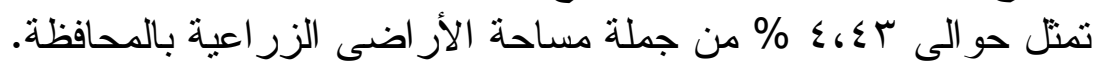

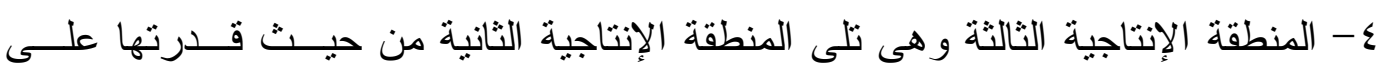

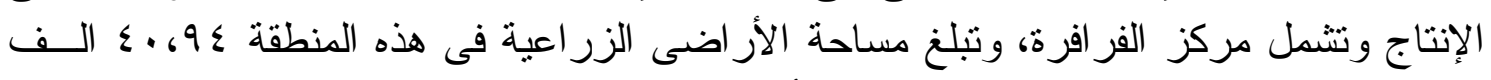

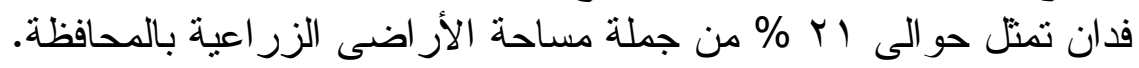

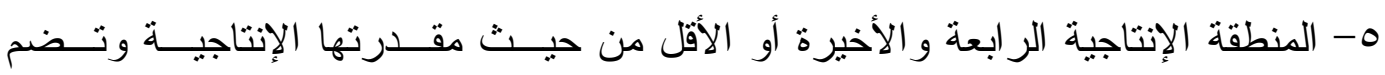

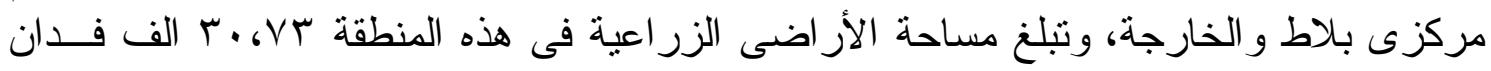

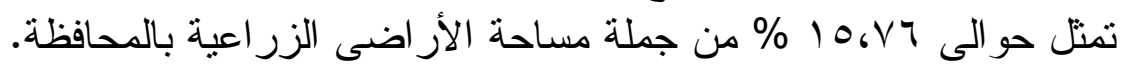

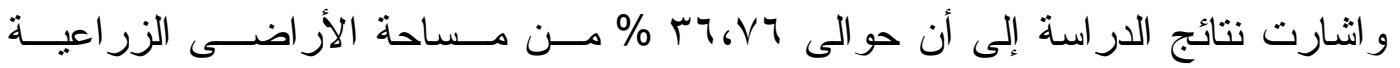

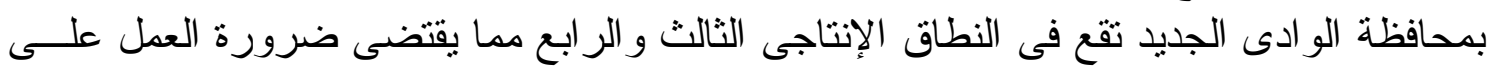

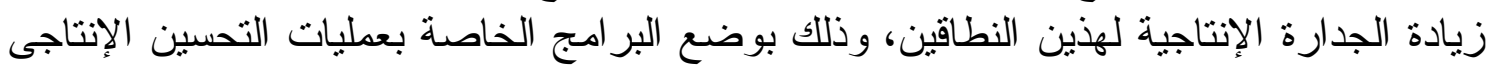

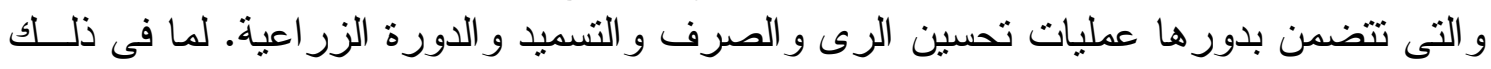
من تحسين خصوبة هذه الأر اضى وبالتالى رفع جدارتها لنها الإنتاجية.

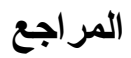

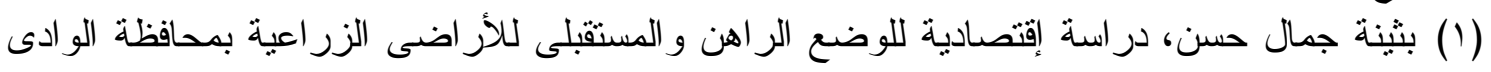

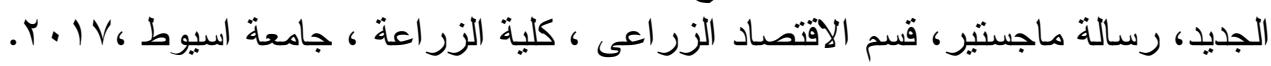

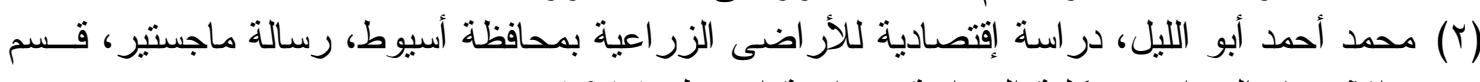

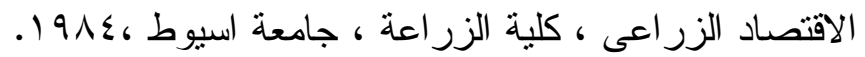

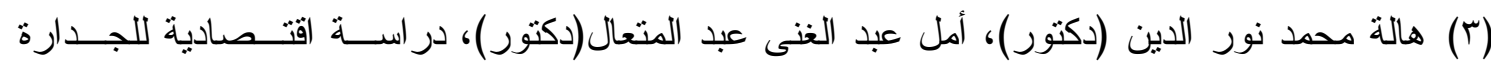

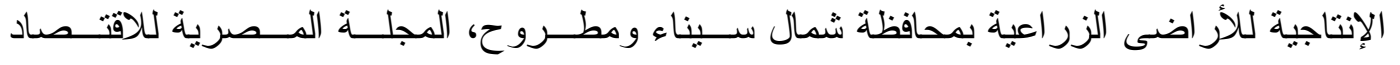

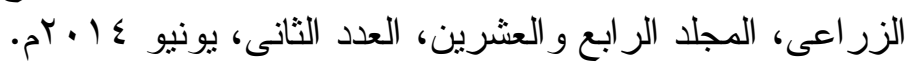




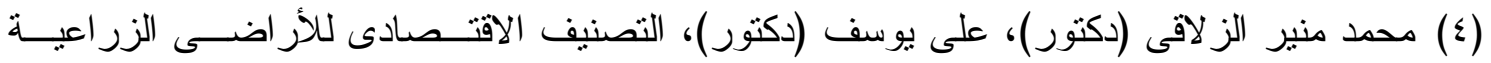

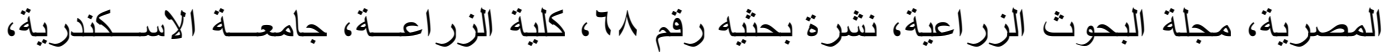

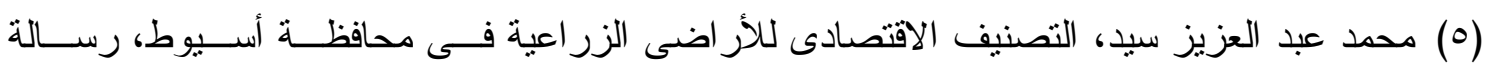

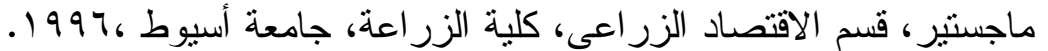

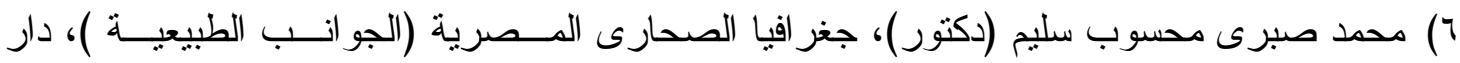

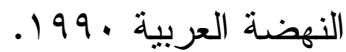

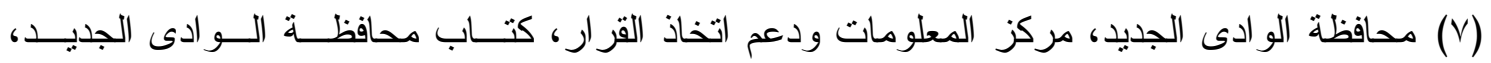
.$r \cdot 10$

(^) هيدى على حسن أحمد، التزكيب المحصولى الحالى و الأوفق فى محافظة أسيوط، رسالة دكتهـور اه،

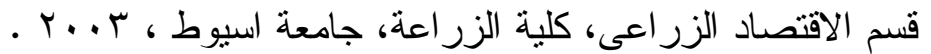




\title{
An Economic Study of Agricultural Land Productivity in New Valley Governorate
}

\section{G.A. EL-Sogheir; M.A.Abou-Nahoal;T.H. Ismail and Buthaina G.H.Sabra}

Department of Agricltural Economics, Faculty of Agricltural, Assiut University

\begin{abstract}
The aim of this study is to classify the agricultural land in New Valley Governorate, on the basis of its productivity for various crops. It was found that, these lands can be classified into four categories, according to their produtivity.

Districts of El- Dakhla had the highest productive land in the Governorate. Next to this category was the land of Paris. the third area included the land of Frafre, and the last category included the land of El- Kharga and Balat district.

The study revealed also that about $36.76 \%$ of the agricultural lands in New Valley Governorate is located in the last two categories. Efforts should be devoted to improve these areas.
\end{abstract}

